Nova Southeastern University NSUWorks

\title{
Water-Soluble Organic Components in Aerosols Associated with Savanna Fires in Southern Africa: Identification, Evolution, and Distribution
}

\author{
Song Gao \\ University of Washington -Seattle Campus, sg1002@nova.edu \\ Dean A. Hegg \\ University of Washington - Seattle Campus \\ Peter V. Hobbs \\ University of Washington - Seattle Campus \\ Thomas W. Kirchstetter \\ Lawrence Berkeley National Laboratory \\ Brian I. Magi \\ University of Washington - Seattle Campus \\ See next page for additional authors
}

Follow this and additional works at: https://nsuworks.nova.edu/cnso_chemphys_facarticles Part of the Environmental Chemistry Commons

\section{NSUWorks Citation}

Gao, S., Hegg, D. A., Hobbs, P. V., Kirchstetter, T. W., Magi, B. I., \& Sadilek, M. (2003). Water-Soluble Organic Components in Aerosols Associated with Savanna Fires in Southern Africa: Identification, Evolution, and Distribution. Journal of Geophysical Research: Atmospheres, 108, (D13), SAF 27-1 - SAF 21-16. https://doi.org/10.1029/2002JD002324. Retrieved from https://nsuworks.nova.edu/cnso_chemphys_facarticles/148 


\section{Authors}

Song Gao, Dean A. Hegg, Peter V. Hobbs, Thomas W. Kirchstetter, Brian I. Magi, and Martin Sadilek 


\title{
Water-soluble organic components in aerosols associated with savanna fires in southern Africa: Identification, evolution, and distribution
}

\author{
Song Gao, ${ }^{1}$ Dean A. Hegg, ${ }^{2}$ Peter V. Hobbs, ${ }^{2}$ Thomas W. Kirchstetter, ${ }^{3}$ Brian I. Magi, ${ }^{2}$ \\ and Martin Sadilek ${ }^{1}$ \\ Received 15 March 2002; revised 18 June 2002; accepted 19 June 2002; published 29 March 2003.
}

[1] During the SAFARI 2000 field campaign, both smoke aerosols from savanna fires and haze aerosols in the boundary layer and in the free troposphere were collected from an aircraft in southern Africa. These aerosol samples were analyzed for their water-soluble chemical components, particularly the organic species. A novel technique, electrospray ionization-ion trap mass spectrometry, was used concurrently with an ion chromatography system to analyze for carbohydrate species. Seven carbohydrates, seven organic acids, five metallic elements, and three inorganic anions were identified and quantified. On the average, these 22 species comprised $36 \%$ and $27 \%$ of the total aerosol mass in haze and smoke aerosols, respectively. For the smoke aerosols, levoglucosan was the most abundant carbohydrate species, while gluconic acid was tentatively identified as the most abundant organic acid. The mass abundance and possible source of each class of identified species are discussed, along with their possible formation pathways. The combustion phase of a fire had an impact on the chemical composition of the emitted aerosols. Secondary formation of sulfate, nitrate, levoglucosan, and several organic acids occurred during the initial aging of smoke aerosols. It is likely that under certain conditions, some carbohydrate species in smoke aerosols, such as levoglucosan, were converted to organic acids during upward transport. INDEX TERMS: 0305 Atmospheric Composition and Structure: Aerosols and particles $(0345,4801) ; 0345$ Atmospheric Composition and Structure: Pollutionurban and regional (0305); 0365 Atmospheric Composition and Structure: Troposphere-composition and chemistry; 0394 Atmospheric Composition and Structure: Instruments and techniques; KEYWORDS: aerosols, biomass burning, organics

Citation: Gao, S., D. A. Hegg, P. V. Hobbs, T. W. Kirchstetter, B. I. Magi, and M. Sadilek, Water-soluble organic components in aerosols associated with savanna fires in southern Africa: Identification, evolution, and distribution, J. Geophys. Res., 108(D13), 8491, doi:10.1029/2002JD002324, 2003.

\section{Introduction}

[2] It is now widely recognized that the emissions of gases and aerosols from biomass burning affect both the chemical properties of the atmosphere and the radiative balance of the Earth on a regional or even global scale [Crutzen and Andreae, 1990; Liousse et al., 1995]. Observational studies have shown elevated levels of $\mathrm{O}_{3}, \mathrm{CO}$, and other trace gases over vast regions from Africa to South America, the tropical Atlantic, the Indian Ocean, and the Pacific [e.g., Andreae and Merlet, 2001]. Recent estimates suggest that biomass burning may be the second largest source of anthropogenic aerosols, next to the production of sulfate from $\mathrm{SO}_{2}$ [Andreae et al., 1996; Liousse et al., 1996]. Aerosols perturb the global radiative balance, and

\footnotetext{
${ }^{1}$ Department of Chemistry, University of Washington, Seattle, Washington, USA.

${ }^{2}$ Department of Atmospheric Sciences, University of Washington, Seattle, Washington, USA.

${ }^{3}$ Lawrence Berkeley National Laboratory, Berkeley, California, USA.

Copyright 2003 by the American Geophysical Union. 0148-0227/03/2002JD002324
}

thus the climate, through backscattering and absorbing of incident sunlight (direct effect) and modification of cloud properties (indirect effect). However, of all climate forcings, aerosols have the largest uncertainty [Intergovernmental Panel on Climate Change (IPCC) Working Group I, 2001]. Recently, much attention has been paid to the chemical composition of aerosols, since their chemical properties are closely coupled with their radiative effects. For example, a large portion of biomass burning aerosols is speculated to be hydrophilic organic species that may increase the aerosols' ability to act as cloud condensation nuclei $(\mathrm{CCN})$, thus inducing a possible change in the regional cloud cover [Ruellan et al., 1999]. Since biomass burning aerosols comprise such a large fraction of anthropogenic aerosols, it is important to better understand their chemical composition.

[3] More than $80 \%$ of the biomass burning occurs in tropical regions. Furthermore, it is estimated that more than $30 \%$ of the tropical biomass is burned during savanna fires in Africa [Andreae, 1991; Lacaux et al., 1993]. To better characterize the physical and chemical properties of aerosols and trace gases from African fire emissions, several large field campaigns have been carried out in recent years, 
as summarized by Andreae and Merlet [2001]. However, these field investigations, as well as several laboratory studies, have revealed the chemical composition of gaseous species in much more detail than that of aerosol species [Crutzen and Andreae, 1990; Yokelson et al., 1996, 1997]. A particularly striking gap in our knowledge is the poor understanding of the molecular composition of organic species in aerosols. Typically, only $10 \%$ or less (by mass) of total aerosol organics has been resolved into individual compounds, although previous studies show that at least $60 \%$ of the African savanna burning aerosols, mostly submicron particles, could be organic species [Saxena and Hildemann, 1996; Cachier et al., 1995]. In previous field campaigns, acetate, formate, and oxalate appear to be the only major particulate organic species that were identified and quantified [Andreae et al., 1998; Ruellan et al., 1999; Reid et al., 1998]. One reason for this knowledge gap seems to be a lack of analytical techniques to target the numerous classes of organic compounds. The most often used technique, gas chromatography-mass spectrometry (GC-MS), can only detect relatively nonpolar species; ion chromatography, another widely used technique, is generally employed to identify only simple organic acids. Indeed, some recent studies utilizing techniques more compatible with polar compounds have found a substantial amount of water soluble organic carbon in atmospheric aerosols, although chemical speciation of individual compounds was not attempted [e.g., Decesari et al., 2000; Facchini et al., 2000]. Therefore, it is necessary to explore the use of new analytical techniques for aerosol organic speciation. In the case of biomass burning aerosols, an important task is to speciate water-soluble species, since these comprise a significant portion of the aerosols and have been postulated to increase their CCN activity [Rogers et al., 1991; Novakov and Corrigan, 1996].

[4] The current study attempts to fill this gap in knowledge on the organic composition of biomass burning aerosols. During the Southern African Regional Science Initiative 2000 (SAFARI 2000) field campaign, fifty or so aerosol samples were collected from an aircraft in plumes at various distances from savanna fire sources as well as in related haze layers in southern Africa. We report here the chemical composition of these aerosols and, in particular, we describe how a fairly new technique, electrospray ionization mass spectrometry (ESI-MS), was utilized for speciation and quantification of a number of carbohydrate species. Our data also indicate some relationship between combustion conditions (flaming versus smoldering) and the chemical composition of smoke aerosols. We then discuss some smoke aerosol aging processes observed in the initial hour after aerosol emissions. Finally, we present some spatial distribution patterns of aerosol organic components, which imply possible chemical transformations during the upward transport of aerosols.

\section{Experimental}

\subsection{Sampling}

[5] The centerpiece of SAFARI 2000 was a large regional field study carried out in southern Africa in August and September 2000. The University of Washington's Convair580 research aircraft was flown in five southern African countries, i.e., South Africa, Mozambique, Zimbabwe, Botswana, and Namibia, for airborne sampling of gases and aerosols from various savanna fires. Fourteen aerosol samples were collected from the Convair-580 in smoke emitted from savanna fires, either directly above the fires or at some distance from the fires. Also collected were 36 aerosol samples in haze layers ranging in height from the surface to $\sim 4.8 \mathrm{~km}$ above sea level. Some of the haze samples were associated with fires, while others were considered regional background samples. The aerosol samples were collected on Teflon membrane filters (lower size limit of about $30 \mathrm{~nm}$ in diameter), which were immediately sealed and stored at about $5^{\circ} \mathrm{C}$ and were later subjected to a series of laboratory analyses to determine their chemical composition. To test the cleanliness of the Teflon filters, a series of tests was conducted in which both untreated and preleached (for 12 hours in triple-distilled, dionized water) filters were analyzed. Both the treated and untreated filters had very low and indistinguishable blanks, a finding which was confirmed by the low signal levels found on our field blanks during the SAFARI campaign. On many flights, aerosol samples were also collected on prebaked quartz filters, often simultaneously with the Teflon filters, for total carbon and black carbon analyses. The sampling system onboard the Convair-580 had an intake cutoff size of about $5 \mu \mathrm{m}$ (in diameter) when utilized in the "grab-bag" mode for collecting smoke aerosol samples. In this sampling mode, a $2.5 \mathrm{~m}^{3}$ electrically conducting plastic (Velostat) bag was rapidly filled with the ambient air. With a $12 \mathrm{~s}$ fill time, the bag sampler was able to capture a relatively large volume of smoke during the short time it took the aircraft to pass through a fire plume. The captured smoke was subsequently drawn through the filters as well as analyzed by other instruments on board. The loss of particles to walls of the bag was estimated to be less than $10 \%$. Aerosols in haze layers were drawn into the sampling system continuously and immediately collected on the filters downstream. The inlet cutoff in this mode is not clear due to a discrepancy between the intake and filter flows. As a result, comparisons between smoke and haze samples must be made with caution.

\subsection{Chemical Analyses of Aerosol Samples}

[6] In the laboratory, the Teflon filter samples were weighed gravimetrically in a clean box where the temperature was kept at $20^{\circ} \mathrm{C}$ and the relative humidity at a nominal $40 \%$. The total aerosol mass for each haze layer and plume sample was corrected by subtracting the average mass of field blanks. The typical total aerosol mass ranged from 60 to $265 \mu \mathrm{g}$, with a measurement uncertainty of $\pm 6 \mu \mathrm{g}$. The precision for these measurements was within $\pm 5 \%$. Each Teflon filter was then extracted by $10 \mathrm{~mL}$ of deionized water (HPLC grade) through mechanical shaking for 20 min. The filter extract was divided into three aliquots for the chemical analyses described below.

[7] The first aliquot was analyzed for metallic elements by an inductively coupled plasma-atomic emission spectrometer (ICP-AES, model Jarrell Ash 955). K, Na, Ca, Mg, and $\mathrm{Fe}$ were identified and quantified, with measurement precision ranging from $\pm 2 \%$ to $\pm 9 \%$. Both the soluble and particulate portions of these elements in the filter extract were excited by the Argon plasma, and were together 
quantified by the ICP-AES. As will be discussed later, some $\mathrm{Ca}, \mathrm{Mg}$, and $\mathrm{Fe}$ could come from the soil dust that was entrained into smoke plumes by turbulence during combustion, in which case they would be mostly in their oxide forms and not entirely soluble.

[8] The second aliquot was analyzed for the water-soluble anionic species by a standard ion chromatography (IC) system (model DIONEX DX-500). A potassium hydroxide gradient elution was employed using an IonPac AS11 anion exchange column, with the eluent's $\mathrm{pH}$ increasing gradually from 10.7 to 11.7 in $3 \mathrm{~min}$ and then from 11.7 to 12.2 in 8 min. With a conductivity detector, three inorganic anions and seven organic acids in their anionic forms were identified, based on the comparisons of retention times of eluted species with those of the standards. They were quantified with regression equations obtained from standard runs. The inorganic anions, i.e., chloride, nitrate, and sulfate, were measured with a precision better than $\pm 5 \%$. The organic acid anions, i.e., acetate, formate, oxalate, malonate, succinate, glutarate, and gluconate, were measured with a precision of either $\pm 10 \%$ (first three species) or $\pm 20 \%$ (latter four species), on the average. Field and control blanks were applied to all of the measurements and calculations. The detection of gluconate is still tentative since the IC retention time does not fully confirm the molecular structure of an unknown species detected in a chromatogram. However, as will be discussed in section 3.1., both mechanistic considerations and the ESI mass spectrometry results suggest that gluconate is a good candidate, or at least a reasonable surrogate, for this species, which may have derived from the combustion of cellulose material.

[9] The third aliquot was analyzed for carbohydrate species by an electrospray ionization-ion trap mass spectrometer (Bruker/Hewlett-Packard, model Esquire LC). Seven carbohydrates (serving as representatives for all possible isomers), i.e., levoglucosan, 1,4:3,6-dianhydro- $\alpha$ d-glucopyranose, levoglucosenone, glucose, mannitol, xylitol, and glycerol, were identified. The detection of levoglucosan is particularly noteworthy since this carbohydrate has previously been suggested as a major component of biomass smoke based on GC-MS analysis [Simoneit et al., 1999]. The presence of some of these species was confirmed by an ion chromatography system with a pulsed amperometric detector. The ESI-MS data also yielded quantitative results for these species, with measurement precision ranging from $\pm 2 \%$ to $\pm 12 \%$. As this is perhaps the first time the ESI-MS and IC-PAD have been concurrently used to analyze for carbohydrates, we next describe this method in detail. We also show some analytical results from this new method.

\subsection{Identification and Quantification of Carbohydrates With the ESI-MS and IC-PAD}

[10] Previous field projects in Africa and South America did not analyze for carbohydrate species in smoke aerosols [e.g., Andreae et al., 1998; Reid et al., 1998]. However, from a mechanistic point of view, carbohydrates should be significant aerosol components from biomass burning. During combustion, cellulose and hemicellulose, together typically comprising $50-70 \%$ of dry biomass [Andreae and Merlet, 2001], can break down to smaller organic species, including polysaccharides, monosaccharides, and their derivatives. Indeed, several laboratory studies have shown that a large number of carbohydrate species could be present in aerosols from pyrolysis [e.g., Shafizadeh, 1982; Pouwels et al., 1989]. As discussed earlier, an intrinsic reason that these species have not been identified in ambient aerosols could be a lack of suitable analytical techniques.

[11] To investigate the presence of carbohydrates in biomass burning aerosols, an ion trap mass spectrometer with an electrospray ionization source was used to analyze the airborne aerosol samples collected during SAFARI 2000. Electrospray ionization is a powerful soft-ionization technique for analyzing polar, involatile compounds [Gaskell, 1997]. The positive ions are produced by the addition of suitable, charged particles in the solution, most commonly protons or alkali metal cations. The resultant pseudomolecular ions have low internal excitation and do not fragment during analysis, allowing sensitive molecular weight determination. Figure 1 shows the schematics of the ESI-MS that was used. A solution of sample and solvent is sprayed through a needle into the spray chamber (a), where a highvoltage electrostatic gradient assists in the production of droplets and ions. A heated drying gas is introduced into the spray chamber to help desolvate the droplets. The formed ions are then transferred through a glass capillary and the ion focusing and transport region (b) to the ion trap mass analyzer (c). The ESI-MS is in itself a rather new technique, only in use for the analyses of environmental samples and biomolecules for the last 15 years or so [e.g., Barinaga et al., 1989; Chapman et al., 1990; Maruyama et al., 2000]. It is therefore necessary to first establish the feasibility of such an analysis for our target compounds.

[12] The ESI-MS demonstrated excellent linear responses to levoglucosan, glucose, mannitol, xylitol, and glycerol standards over a wide range of concentrations $(60 \mathrm{ppb}$ to $2500 \mathrm{ppb}$ ), with $\mathrm{R}^{2}$ values for regressions of 0.9836 , $0.9696,0.9965,0.9818$, and 0.9123 , respectively. This was achieved by using flow injection to infuse a $10 \mu \mathrm{l}$ plug of analyte solution into the mass spectrometer, which was optimized for highest sensitivity and no fragmentation. The standard solutions were natriated by $5 \mathrm{ppm} \mathrm{Na}^{+}$to ionize the carbohydrates before injection. The mass spectra were collected over a mass range of $50-300 \mathrm{~m} / \mathrm{z}$ (mass to charge ratio) at $1 \mathrm{scan} / \mathrm{s}$ and were averaged over the elution profile ( $\sim 40$ s) to obtain the final spectra. The abundances were used for construction of standard regression curves. Figure 2 shows the ESI mass spectrum of a standard mixture solution, displaying $\mathrm{Na}^{+}$adducts of $1500 \mathrm{ppb}$ of levoglucosan, glucose, and mannitol. It can be seen that these carbohydrate species did not undergo any fragmentation and the pseudomolecular ions were intact due to the soft nature of electrospray ionization. However, molecular ions alone are generally not adequate enough to confirm molecular structures. For instance, various structural isomers should show the same molecular ions, but they could have different physical properties such as solubility, volatility, or density. Thus, further evidence is needed to differentiate between such species, or at least confirm the major functional groups in the species detected by the ESI-MS.

[13] One can typically isolate and fragment an MS peak of interest and get a second-dimension $\mathrm{MS}^{\wedge} \mathrm{MS}$ spectrum to confirm its molecular identity by the fragmentation patterns. However, these sugar molecules did not provide sufficient 


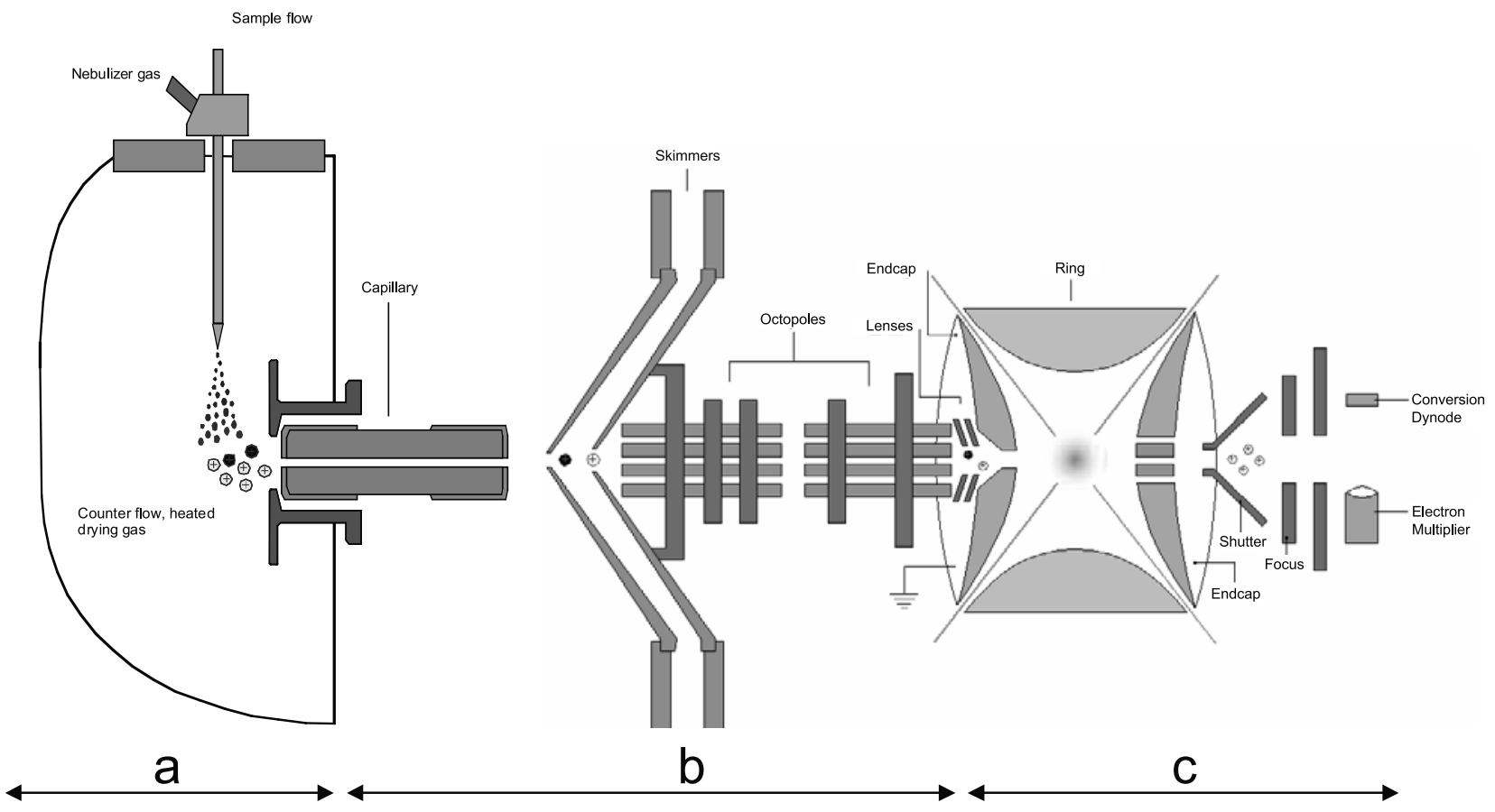

Figure 1. Schematics of the electrospray ionization-ion trap mass spectrometer used in this work. It consists of three main components: (a) spray chamber; (b) ion transport and focusing region; (c) ion trap mass analyzer.

fragmentation for such an analysis. Hence, we used instead an ion chromatography system as a second-dimension detection. To this end, the DX-500 IC system was coupled with a Pulsed Amperometric Detector (PAD), which separates different classes of carbohydrate species. Under certain circumstances, the IC can even resolve some isomer species. Therefore, the IC-PAD retention time can be used to confirm the presence of a specific carbohydrate. The ICPAD responses to various carbohydrate standards also turned out to be very linear, with $\mathrm{R}^{2}$ values for the linear fits always above 0.99 . For each identified compound, we can further calculate the ratio of the response factor of the IC to that of the MS at various standard concentrations. We define such a ratio as the response factor ratio (RFR) which, in principle, should have a constant value, independent of the standard concentration. This was confirmed by laboratory tests on levoglucosan, glucose, and mannitol standards. Furthermore, these tests show that for each specific compound, the mean RFR is a distinctive value with a small variation that does not overlap with that of the other compounds. Therefore, the RFR can be used as a distinctive parameter to help confirm the presence of a speculated compound. By coupling the mass spectrum of a sample and its ion chromatogram, we now have three parameters-mass to charge ratio of molecular ions, chromatographic retention time, and the RFR-to identify and confirm the carbohydrate components.

[14] The filter extracts from SAFARI 2000 were analyzed by the ESI-MS and IC-PAD with the same procedures applied to the standards. As an example, Figure 3 shows the identification of levoglucosenone $(\mathrm{m} / \mathrm{z}=149), 1,4: 3,6-$ dianhydro- $\alpha$-d-glucopyranose (167), xylitol (175), levoglucosan (185), glucose (203), and mannitol (205) on the mass spectrum of the water extract of a hazy sample collected on
10 September, in comparison with the mass spectrum of a typical field blank. Figure 4 shows the ion chromatogram of the same aerosol sample as in Figure 3, confirming the presence of levoglucosan, mannitol, and glucose. The IC resolution was relatively poor in this case, but the peaks identified serve the confirmation purpose well. The RFR calculations further confirmed their presence. Overall, we feel the ESI-MS, and the two-dimensional detection method described above, can yield fairly convincing molecular speciation results. After further development, they could serve as potent tools to identify "unknown" aerosol organic species, particularly the polar and involatile ones. For example, it can be seen from (Figure 3a) that there are a substantial number of peaks in the mass spectrum that have

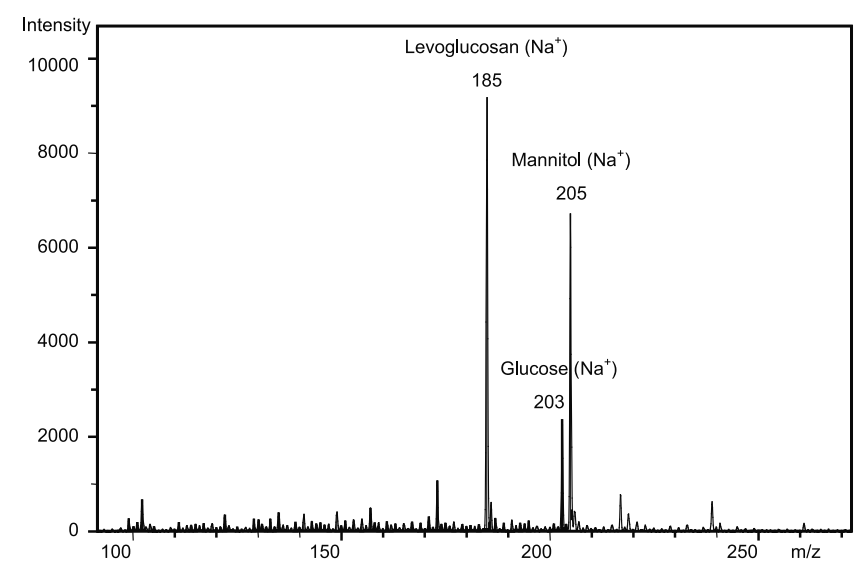

Figure 2. ESI-MS spectrum of a standard mixture solution, displaying the $\mathrm{Na}^{+}$adducts of $1500 \mathrm{ppb}$ of levoglucosan, glucose, and mannitol. 

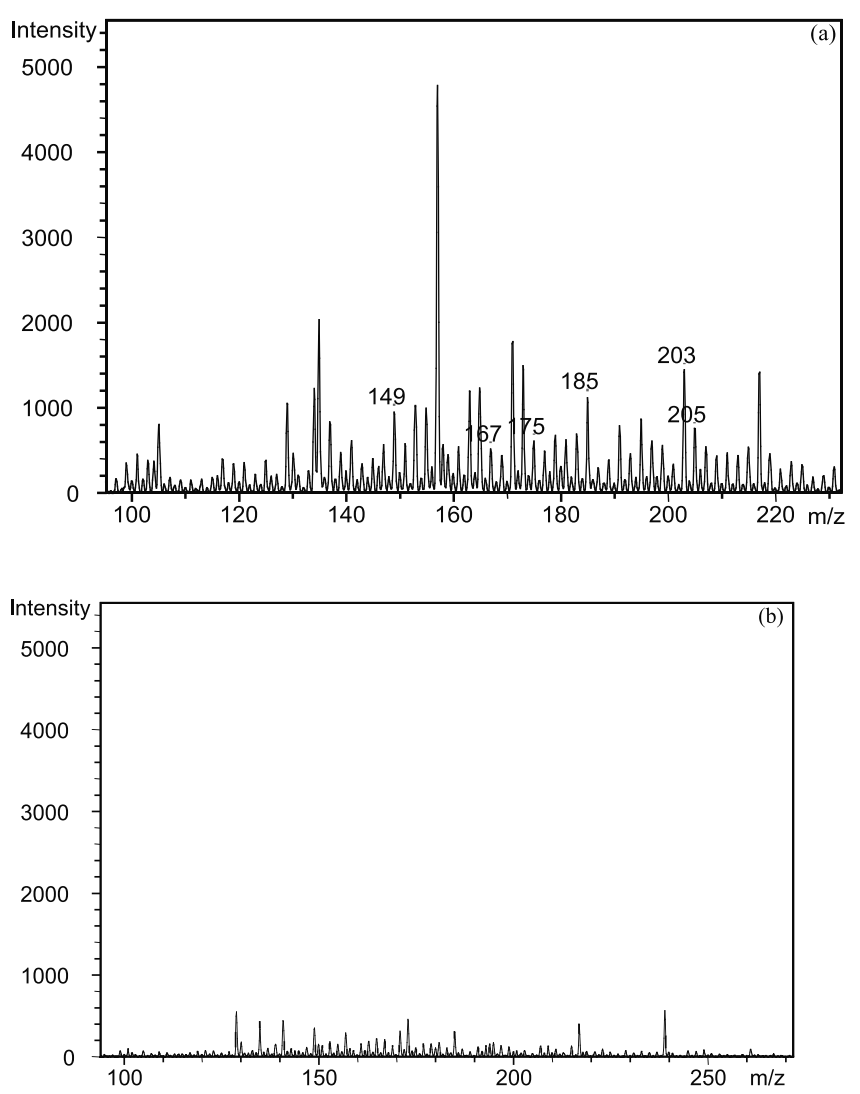

Figure 3. (a) ESI-MS spectrum of the water extract of a haze aerosol sample collected on 10 September 2000, displaying the $\mathrm{Na}^{+}$adducts of levoglucosenone $(\mathrm{m} / \mathrm{z}=149)$, 1,4:3,6-dianhydro- $\alpha$-d-glucopyranose (167), xylitol (175), levoglucosan (185), glucose (203), and mannitol (205), each species serving as a representative of possible isomers; (b) ESI-MS spectrum of a typical field blank. not been identified. This is common for other SAFARI samples, which suggests that aerosols impacted by biomass burning in southern Africa contain many more components than identified in this work, at levels readily detectable by the ESI-MS. While a precise mass estimate of these components would, of course, require speciation, we can roughly assess their importance as follows. Using levoglucosan as a plausible surrogate standard, the unidentified species detected by the MS are estimated to account for up to $30 \%$ and $10 \%$ of the smoke and haze aerosol mass, respectively. These figures are comparable to those for the organic species already identified. The actual chemical nature of these unidentified species can be explored in the near future by testing standard compounds suggested by previous laboratory studies [e.g., Pouwels et al., 1989] and/ or mechanistic considerations, and by matching of $\mathrm{m} / \mathrm{z} \mathrm{MS}$ peaks and IC retention times.

[15] Since the IC had lower peak resolutions than the MS, the latter was used to quantify the mass concentrations of levoglucosan, glucose, and mannitol in the filter samples. Besides better resolutions, another advantage is that the mass concentrations calculated from molecular ion peaks include stereoisomers of these carbohydrates that could have been produced via the stereochemistry of reactions during biomass burning. These isomers (e.g., glucose and mannose) have almost identical physical and chemical properties and thus can be quantified as one molecular species. They are expected to play very similar roles in aerosol and cloud processes.

[16] In the mass spectra of some plume samples, there were prominent peaks at $\mathrm{m} / \mathrm{z}$ of 167 and 149. These two molecular ions correspond with two anhydrosugars that have been identified as cellulose combustion products in previous laboratory studies, i.e., 1,4:3,6-dianhydro- $\alpha$-dglucopyranose and levoglucosenone [Shafizadeh, 1982; Pouwels et al., 1989]. Their possible presence is also supported by the fact that we often see peaks adjacent to

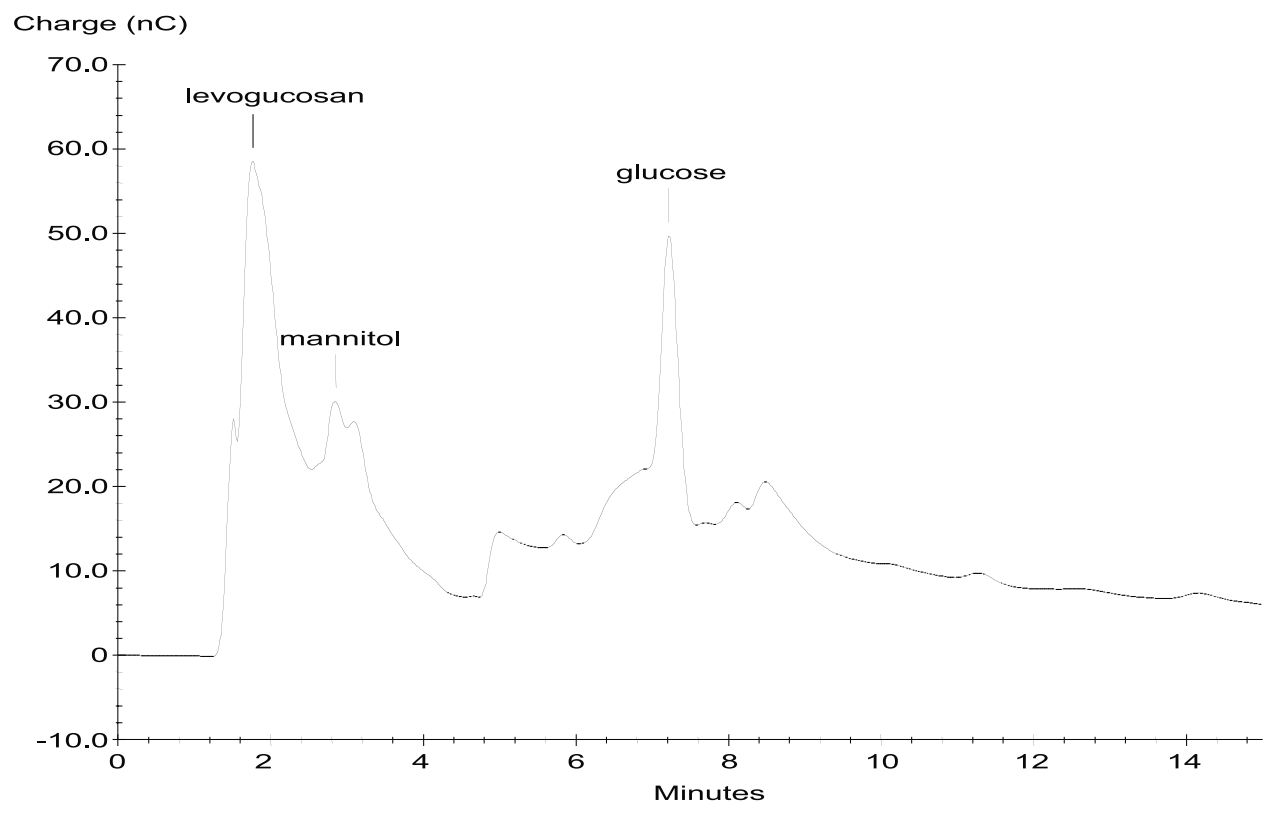

Figure 4. Ion chromatogram of the water extract of the same sample as in (Figure 3a), confirming the presence of levoglucosan, mannitol, and glucose. 
levoglucosan in the ion chromatograms. Due to the unavailability of standards, we used levoglucosan as a surrogate to quantify the other two anhydrosugars. Additionally, mannitol (a C6 polyol), as well as glucose which is the monomer unit of cellulose, were positively identified in some SAFARI 2000 samples by both the MS and IC, and were subsequently quantified. C5 and C3 polyols were detected in some samples by the MS in terms of molecular ions, but were barely confirmed by the IC due to poor resolutions. We used xylitol and glycerol as surrogates to quantify these species, but further tests on their presence and exact structures are needed. The possible presence of these polyols in the atmosphere was suggested by Graedel et al. [1986] and Wauters et al. [1979]. The molecular structures of the identified carbohydrates, each representing the stereoisomers possibly present, are given in Figure 5, along with the structures of gluconic acid, cellulose, hemicellulose, and cellobiosan.

\section{Results and Discussion}

\subsection{Chemical Composition of Smoke and Haze Aerosols}

[17] Four classes of chemical species were identified in the smoke and haze layer aerosols associated with savanna burning in southern Africa, i.e., metallic elements, inorganic anions, organic acid anions, and carbohydrates. First we shall compare some of our measurements with those made in a previous field study in southern Africa in 1992 [Andreae et al., 1998]. Then we shall discuss the mass abundance of each class of compounds in both plumes and haze layers, along with their possible sources.

[18] Andreae et al. used two-stage stacked filter pairs to collect coarse and fine particles directly over several biomass fires. The filters for the coarse fraction had a $50 \%$ cutoff diameter of $1.2 \mu \mathrm{m}$, and the filters for the fine fraction efficiently collected particles down to $30 \mathrm{~nm}$ in diameter, which is almost identical to the lower cutoff for the SAFARI 2000 samples. Although Andreae et al. [1998] did not document their sampling system's inlet cutoff size, we assume it to have been similar to that aboard the Convair580 in the "grab-bag" mode, namely, about $5 \mu \mathrm{m}$. With this assumption, it is possible to compare the chemical measurements in the two field projects that sampled very similar vegetation types in the same region. Following Andreae et al. [1998], we calculated the mole fractions of chloride, nitrate, sulfate, oxalate, $\mathrm{K}^{+}, \mathrm{Na}^{+}, \mathrm{Ca}^{2+}$, and $\mathrm{Mg}^{2+}$ in the total identified soluble ionic species content (defined as the sum of the above eight species plus ammonium, representing the major ionic species) in smoke aerosols. Since ammonium was not measured onboard the Convair-580 during SAFARI 2000, we use the $\mathrm{K}^{+}$results to estimate the ammonium content as suggested by Andreae et al. [1998]. There were nine smoke aerosol samples collected directly over savanna fires in SAFARI 2000. The (inter-sample) average and standard deviation of the mole fraction of each species are given in Table 1. We combined the fine and coarse fractions given by Andreae et al. [1998] and list in Table 1 values from their two fire cases, together giving an estimated range of mole fractions of each species during SAFARI-92. It can be seen that all species agree reasonably well, when taking into account measurement uncertainties. In SAFARI 2000, the $\mathrm{Na}^{+}, \mathrm{Ca}^{2+}$, and $\mathrm{Mg}^{2+}$ mole fractions varied widely from sample to sample, as seen from the large standard deviations. For $\mathrm{Na}^{+}$, these fluctuations could be caused in part by possible contamination from the glass vials used for the ICP-AES measurements. For $\mathrm{Ca}^{2+}$ and $\mathrm{Mg}^{2+}$, some of which could come from soil dust entrained into the smoke aerosols, the varying fire intensities could have contributed to the different mole fractions in different samples, as seen in both projects. Difference between the two sampling systems could also have caused some difference in results, especially for the coarse particles. However, the overall excellent agreement between the two campaigns shows the good quality of analytical measurements.

[19] A more complete picture of how these different chemical species are distributed in the aerosols can be seen from their fractional contributions to the total aerosol mass. Figure 6 shows the mass fractions of four classes of chemical species in 13 smoke aerosol samples, collected directly above and downwind of fires in SAFARI 2000. Figure 7 shows such results in 33 haze layer samples, ranging from the surface to the free troposphere. In the haze samples, $14-78 \%$ (on the average, $36 \%$ ) of the total aerosol content was resolved into individual chemical species; while not entirely comparable due to the differing inlet cutoff, in the smoke samples, $13-47 \%$ (on the average, $27 \%$ ) of the total aerosol content was resolved into individual chemical species. Furthermore, in haze layers, the identified inorganics, including chloride, sulfate, nitrate, $\mathrm{K}$, $\mathrm{Na}, \mathrm{Fe}, \mathrm{Ca}$, and $\mathrm{Mg}$, comprise more than $30 \%$ of the total aerosol mass in about half of the aerosol samples. In comparison, in only one out of the 13 smoke samples did the identified inorganics comprise more than $30 \%$ of the total aerosol mass. Since the unanalyzed trace elements, such as $\mathrm{Si}, \mathrm{Al}, \mathrm{P}, \mathrm{Ti}, \mathrm{Mn}, \mathrm{Cu}$, and $\mathrm{Zn}$, are expected to comprise no more than $5 \%$ of the total aerosol mass [Gaudichet et al., 1995], most of the inorganic mass has been accounted for by our measurements. The above difference in the aerosol inorganic fraction then suggests that smoke aerosols may have a higher fraction of carbonaceous species than haze aerosols. As will be discussed later, both the loss of some organic species to the gas phase and the secondary formation of sulfate, nitrate, and other inorganic species, during aerosol upward transport, could have contributed to this difference. However, this difference may also simply be a sampling artifact due to the enhanced collection of larger particle when the sampling system was used to collect haze aerosols, coupled with a likely higher mass fraction of inorganics in larger particles. On the other hand, one commonality that aerosols in haze and in smoke share is that carbonaceous species typically constitute at least half of the total aerosol mass. This can be seen from Figures 6 and 7, which show that the inorganic mass fractions were almost always lower than $50 \%$. This again highlights the abundance and importance of organic species and black carbon in atmospheric aerosols, as other recent observations have suggested [e.g., Novakov et al., 1997]. The organic species identified here, including seven organic acids and seven carbohydrates (along with their isomers), comprise from 1 to $31 \%$ of the total aerosol mass of all samples. Interestingly, this fraction is consistently high in aerosols from smoldering fires and in aged smoke aerosols, typically ranging from 13 to $18 \%$. 


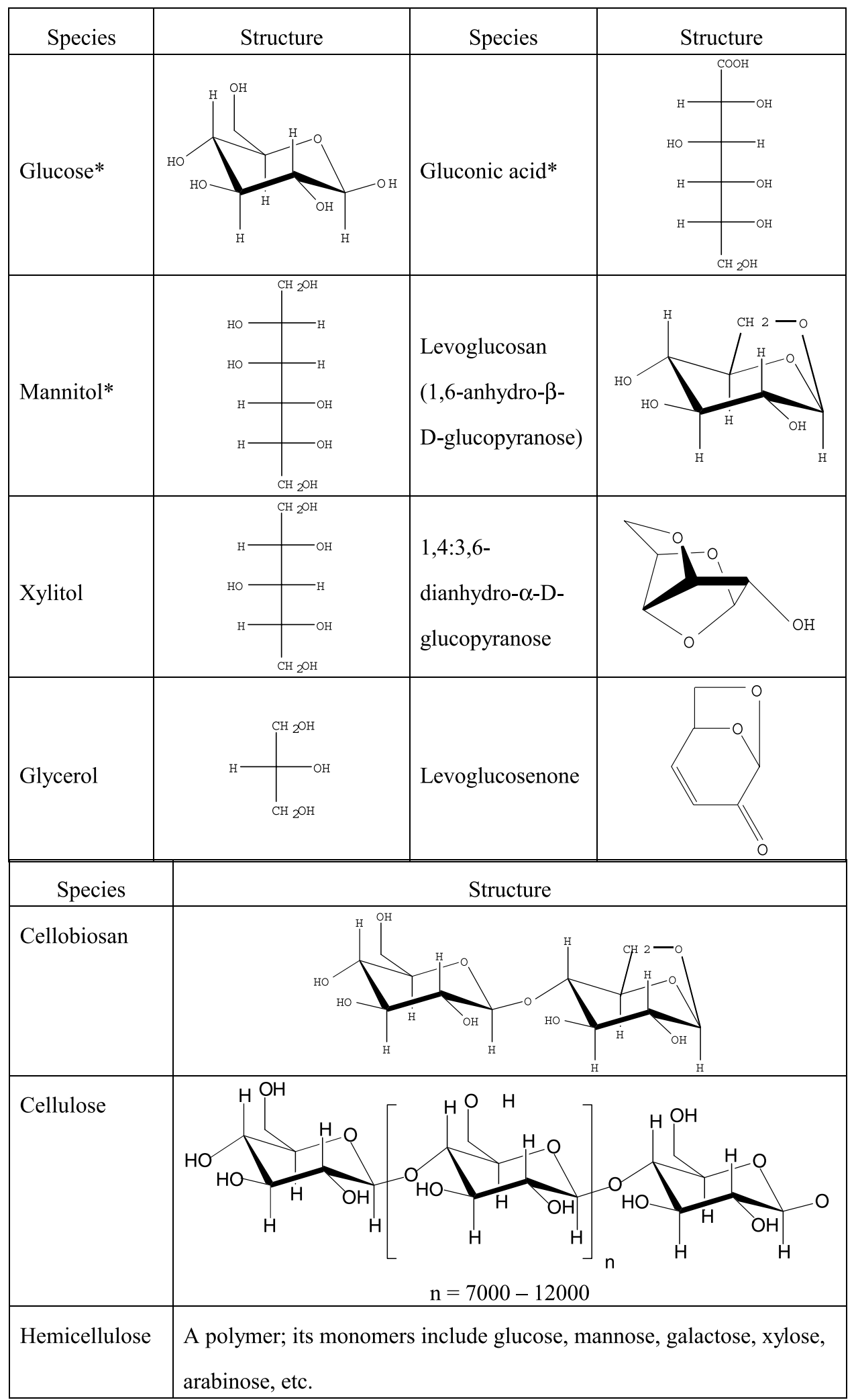

Figure 5. Molecular structures of identified and relevant carbohydrate species in savanna burning aerosol in SAFARI 2000. An asterisk denotes that only the D-enantiomers of these species are depicted here. However, both D- and L- isomers were quantified together by the ESI-MS and are expected to play almost identical roles in the aerosol and cloud processes discussed in this paper. 
Table 1. Comparison of the Mole Fractions ${ }^{\mathrm{a}}$ of Some Identified Smoke Species in SAFARI 2000 With Those Reported by Andreae et al. [1998] in SAFARI-92

\begin{tabular}{lcccccccc}
\hline & Chloride, $\%$ & Nitrate, $\%$ & Sulfate, $\%$ & Oxalate, $\%$ & $\mathrm{~K}^{+}, \%$ & $\mathrm{Na}^{+}, \%$ & $\mathrm{Ca}^{2+}, \%$ & $\mathrm{Mg}^{2+}, \%$ \\
\hline SAFARI 2000 (this work) $^{\mathrm{b}}$ & $32( \pm 20)$ & $6( \pm 5)$ & $8( \pm 8)$ & $0.7( \pm 0.7)$ & $19( \pm 6)$ & $8( \pm 14)$ & $7( \pm 14)$ & $2( \pm 3)$ \\
Andreae et al. $[1998]^{\mathrm{c}}$ & $26 \sim 35$ & $2 \sim 5$ & $5 \sim 9$ & $0.5 \sim 1$ & $16 \sim 16$ & $3 \sim 9$ & $7 \sim 23$ & $4 \sim 16$ \\
\hline
\end{tabular}

${ }^{\mathrm{a}}$ Mole fractions are expressed as $\%$ of total soluble ionic species.

${ }^{\mathrm{b}}$ Each value is the average of nine smoke aerosol samples collected directly over savanna fires in southern Africa during SAFARI 2000

${ }^{c}$ The two values are from the two fire cases in the work of Andreae et al. [1998], together giving an estimated range of mole fractions for each species in southern Africa during SAFARI-92.

[20] To examine the mass abundance and contribution of individual species, we show in Table 2 the median mass concentration (with its measurement uncertainty) and range for each quantified species in nine smoke aerosol samples collected directly above fires. For comparison, we also report these quantities for four ambient aerosol samples collected either before the fires were ignited, or, in one case, upwind of the fire. These serve as reference background samples. Total aerosol mass concentration is also presented for both smoke and haze aerosols. The vegetation types of these fires varied from lowvelds and highvelds in South Africa, to woodlands and grasslands in Zambia, to east African coastal mosaic in Mozambique. For those cases where a species was not detected, we report the detection limit (DL). Our discussion below is based on the median values given in Table 2, unless otherwise noted. Since the mass concentrations in the ambient haze were less than $15 \%$ of those in the smoke for most species, the different intake cutoff between the smoke and haze sampling modes should not have significant effects on the comparisons between the two types of samples. Particularly, for organic species, which are all likely concentrated in the submicron size range, this sampling artifact should be even less significant.

[21] Of the three inorganic anions identified, chloride was the dominant species, with a very low background concentration, indicating that chloride predominantly comes from the burning of vegetation. Sulfate was slightly more abundant than nitrate, but both anions had relatively high background concentrations, with a background/smoke fraction of about $20 \%$ and $10 \%$, respectively. This shows that sulfate and nitrate could come directly from biomass burning and/ or from chemical processes during the aging of the smoke, as will be discussed further in section 3.3. Nevertheless, it appears that biomass burning makes a major contribution to these two common species in southern Africa during the dry season.

[22] Of the seven organic acid anions detected, the most abundant species is tentatively identified as gluconate. This

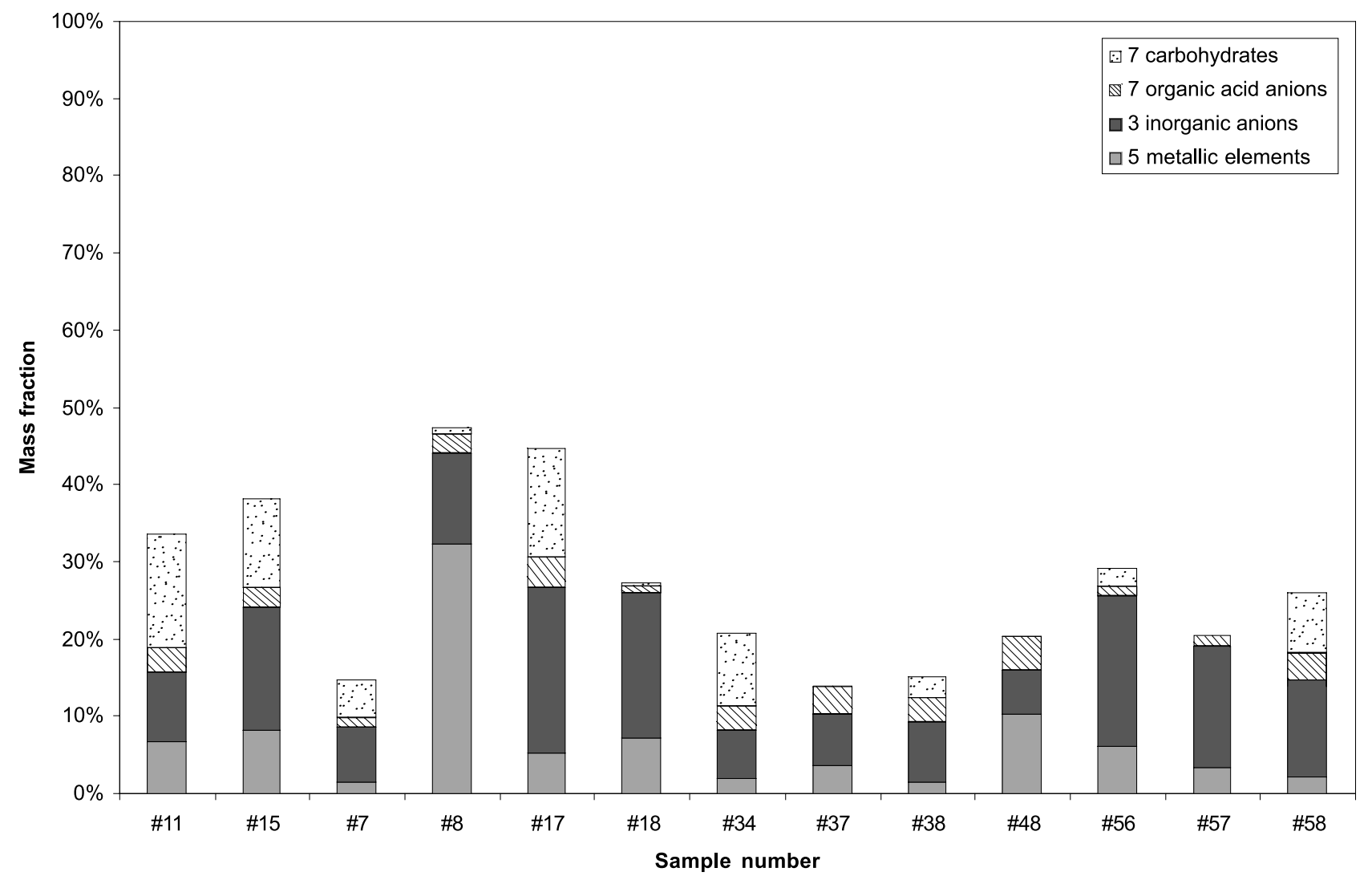

Figure 6. Fractional contributions of four classes of chemical species to the total mass of smoke aerosols in SAFARI 2000. See text for full description of each class. 


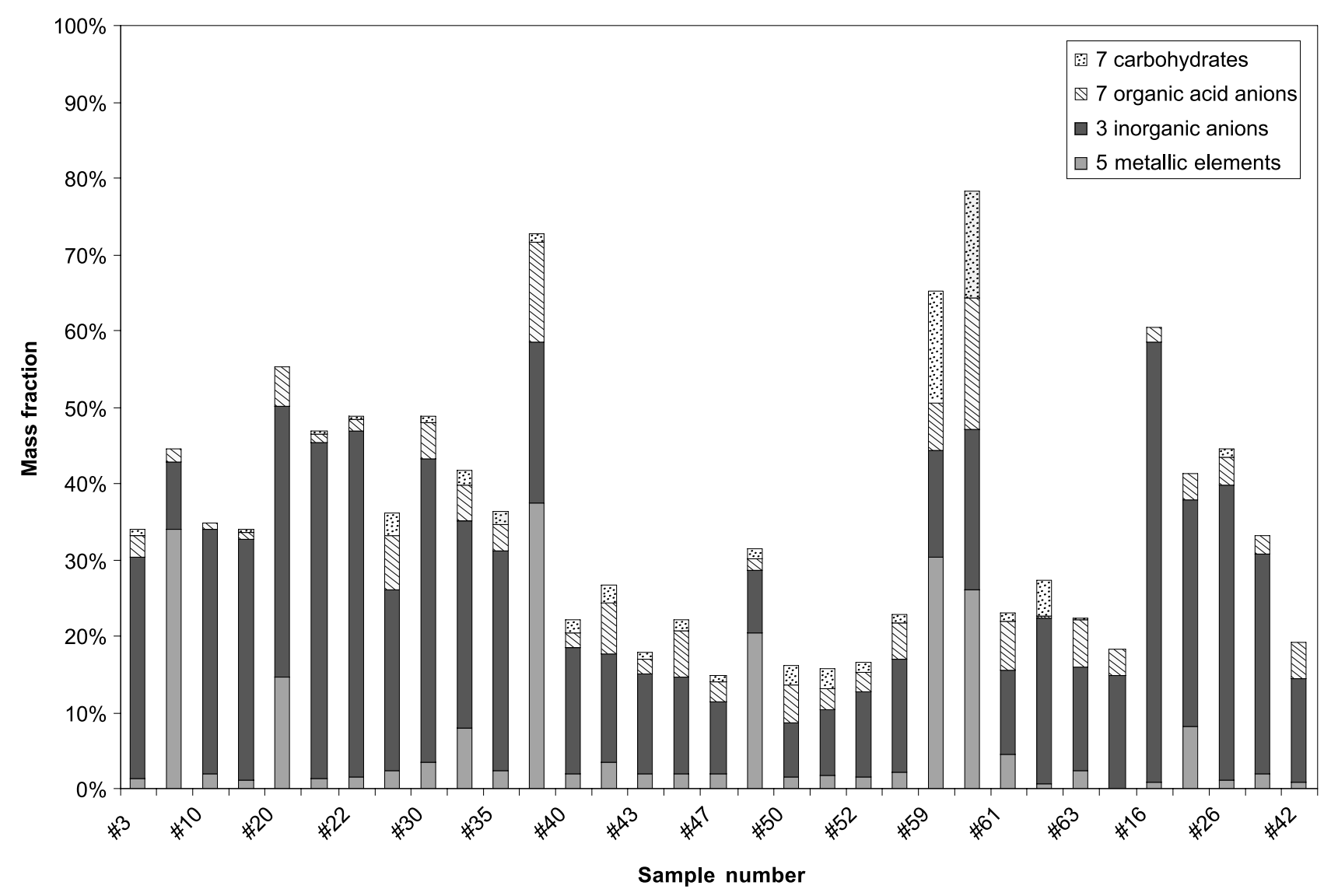

Figure 7. Fractional contributions of four classes of chemical species to the total mass of haze aerosols in SAFARI 2000. See text for full description of each class.

is still speculative since the identification is primarily based on the IC chromatograms. Even though a $\mathrm{m} / \mathrm{z}=219$ peak often shows up in the ESI-MS spectra, which supports the presence of gluconic acid, the sensitivity is not good enough for solid confirmation. Nevertheless, it is well known that gluconic acid is one of the most stable oxidation products of glucose, with a yield sometimes as high as 95\% [Streitwieser and Heathcock, 1985]. Glucose, in turn, is the

Table 2. Median ( \pm Uncertainty) and Range of Mass Concentrations of Identified Species in Smoke Aerosols and Ambient (Background) Aerosols Collected During SAFARI 2000

\begin{tabular}{|c|c|c|c|c|}
\hline \multirow[b]{2}{*}{ Species } & \multicolumn{2}{|c|}{$\begin{array}{c}\text { Smoke Aerosols Collected Directly Over the } \\
\text { Fires-Mass Concentrations of Identified } \\
\text { Chemical Species, } \mu \mathrm{g} / \mathrm{m}^{3}\end{array}$} & \multicolumn{2}{|c|}{$\begin{array}{l}\text { Background Aerosol Samples Collected in the } \\
\text { Ambient Air mass Concentration of Identified } \\
\text { Chemical Species, } \mu \mathrm{g} / \mathrm{m}^{3}\end{array}$} \\
\hline & Median (Uncertainty) & Range & Median (Uncertainty) & Range \\
\hline Total aerosol mass & $473(20)$ & $105-1182$ & $13(1.5)$ & $3.2-25$ \\
\hline Chloride & $27.65(0.21)$ & $0.67-193.48$ & $0.25(0.02)$ & $0.03-0.35$ \\
\hline Nitrate & $4.83(0.02)$ & $1.57-18.48$ & $0.476(0.003)$ & $0.29-1.79$ \\
\hline Sulfate & $10.42(0.57)$ & $1.48-35.94$ & $2.16(0.11)$ & $1.18-8.75$ \\
\hline Gluconate & $4.95(0.44)$ & $1.42-18.16$ & $0.38(0.10)$ & $0.10-0.90$ \\
\hline Acetate & $0.83(0.08)$ & $0.08-6.61$ & \multicolumn{2}{|c|}{ All below the DL $(=0.18)$} \\
\hline Formate & $0.38(0.05)$ & $0.05-2.66$ & \multicolumn{2}{|c|}{ All below the DL $(=0.02)$} \\
\hline Oxalate & $0.75(0.07)$ & $0.195-1.267$ & $0.15(0.03)$ & $0.10-0.47$ \\
\hline Glutarate & $0.30(0.07)$ & $0.07-1.10$ & $0.03(0.01)$ & $0.01-0.1$ \\
\hline Succinate & $0.47(0.07)$ & $0.07-0.94$ & $0.07(0.02)$ & $0.01-0.19$ \\
\hline Malonate & $1.2(0.4)$ & $0.4-2.3$ & $0.21(0.07)$ & $0.07-0.59$ \\
\hline Levoglucosan & $14.83(0.85)$ & $0.50-74.19$ & $0.3(0.1)$ & $0.10-1.03$ \\
\hline Dianhydro-glucopyranose & $0.8(0.1)$ & $0.1-3.8$ & $0.021(0.007)$ & $0.007-0.036$ \\
\hline Levoglucosenone & $0.36(0.12)$ & $0.12-1.06$ & \multicolumn{2}{|c|}{ All below the DL $(=0.02)$} \\
\hline Glucose & $1.77(0.59)$ & $0.59-3.83$ & \multicolumn{2}{|c|}{ All below the DL $(=0.22)$} \\
\hline Mannitol & $1.86(0.62)$ & $0.62-2.15$ & \multicolumn{2}{|c|}{ All below the DL $(=0.24)$} \\
\hline $\mathrm{Na}$ & $6.4(5.8)$ & $5.8-60.91$ & $2.6(1.3)$ & $1.3-4.5$ \\
\hline K & $13.81(0.12)$ & $1.87-70.89$ & $0.31(0.02)$ & $0.06-0.89$ \\
\hline $\mathrm{Ca}$ & $0.145(0.007)$ & $0.01-84.27$ & $0.015(0.002)$ & $0.004-0.034$ \\
\hline $\mathrm{Fe}$ & $0.42(0.24)$ & $0.24-8.20$ & $0.02(0.01)$ & $0.02-0.10$ \\
\hline $\mathrm{Mg}$ & $0.55(0.07)$ & $0.07-8.53$ & $0.028(0.014)$ & $0.02-0.21$ \\
\hline
\end{tabular}


monomer unit of cellulose that comprises $40-50 \%$ of dry biomass [Simoneit et al., 1999; Parham and Gray, 1984]. It is thus quite likely that gluconic acid, perhaps together with its $\gamma$-lactone form, is a characteristic component of smoke aerosols due to its structural stability and low volatility, which is similar to levoglucosan. Since this is the first time gluconic acid has been reported in biomass burning aerosols, and because it could be one of the most abundant acid species, confirmation of its presence should be pursued. Formate and acetate, two monocarboxylic acid anions, made minor contributions to the total aerosol mass. Since they were always below their DLs in the background aerosols, they were likely emitted by the biomass fires. However, as will be discussed in section 3.3, they could also be secondary products generated in the fire plumes. Similarly, the four dicarboxylic acids identified (C2-C5) also make only minor contributions to the total aerosol mass. Oxalic acid was a common component in all nine smoke samples, whereas, malonic acid was detected in only one sample, implying different formation pathways. On the other hand, all four diacids had relatively high background concentrations, which suggests either secondary formation processes during aerosol aging or a nonbiomass burning source.

[23] Of the seven carbohydrate species we identified using representative isomers, xylitol and glycerol are not included in Table 2 due to large measurement uncertainties. They were detected in only two smoke samples and comprised $0.1 \%$ and $1.5 \%$, respectively, of the total aerosol mass. Levoglucosan was the most abundant carbohydrate in the smoke aerosols but, interestingly, only in aerosols emitted from primarily smoldering fires, constituting $5-14 \%$ of the total aerosol mass. It was not detected in aerosols collected over primarily flaming fires, at a DL of $0.2 \mu \mathrm{g} / \mathrm{m} 3$. The other four carbohydrates made much smaller contributions to the smoke aerosol mass, often less than 1\%. Like levoglucosan, they were also mostly detected in the aerosols emitted from primarily smoldering fires. The apparent impact of combustion phase on the aerosol composition is further examined in section 3.2. In addition, in sections 3.2, 3.3, and 3.4, we will discuss the possible chemical pathways for the formation of the identified carbohydrates, as well as organic acids.

[24] Of the five metallic elements identified, $\mathrm{K}$ was the most abundant species, with a very low background concentration, indicating that $\mathrm{K}$ mostly comes from biomass burning. This is in accord with previous studies in southern and western Africa such as SAFARI-92 [Andreae et al., 1998] and DECAFE-FOS [Gaudichet et al., 1995]. Na was found to have somewhat high background concentrations, raising the possibility that there could be transport of $\mathrm{Na}$ from other sources (e.g., oceans) to the sampling region. Sea salt, if present, is estimated to contribute less than $1 \%$ to the smoke aerosol mass. However, the high measurement uncertainties and the few data points make it difficult to be conclusive about the source or even presence of $\mathrm{Na}$. $\mathrm{Ca}$, $\mathrm{Mg}$, and $\mathrm{Fe}$ were very minor species in the smoke aerosols, and were also present in trace amounts in the background aerosols. Previous studies in Africa have suggested that $\mathrm{Ca}$ can have several origins (e.g., soil dust and burning of vegetation) while Fe primarily comes from the remobiliza- tion of soil dust [Gaudichet et al., 1995]. Our data is not inconsistent with these speculations.

\subsection{Impact of Combustion Phase on the Chemical Composition of Savanna Burning Aerosols}

[25] To further examine the possible impact of combustion phase (i.e., flaming and smoldering) of a fire on the chemical composition of the emitted aerosols, we performed two sets of computations.

[26] The first set calculates the fractions of identified organics (carbohydrates and organic acid anions) and inorganics (metallic elements and inorganic anions) in the total aerosol mass. Since the chemical composition evolves during aerosol aging, (see section 3.3), the calculations were carried out only for young smoke aerosols. We also used visual observations made aboard the Convair-580 to assign a primary combustion phase for the nine fires (Figure 6) above which smoke aerosols were collected. Arbitrary as these assignments might be, they are roughly in accordance with the computed combustion efficiencies of the fires, with lower values indicating more smoldering and higher values more flaming combustion. The organic and inorganic mass fractions, together with the combustion phases, are listed in Table 3. It can be seen that smoke aerosols from the primarily smoldering fires had a much higher content of identified organic species (average $\sim 14 \%$ ) than those from the primarily flaming fires (average $\sim 3 \%$ ), whereas, the inorganic fraction does not appear to show such a relationship with combustion phase.

[27] To confirm such a relationship, and to determine if it might be characteristic of only certain classes of species, we normalized the mass concentration of each identified species to the $\mathrm{K}$ concentration in each smoke aerosol sample, following Gaudichet et al. [1995]. Past studies in Africa have shown that $\mathrm{K}$ is predominantly released from the vegetation during biomass burning, the contributions from soil dust and sea salt being very minor [Gaudichet et al., 1995; Andreae et al., 1998]. The results discussed in section 3.1 strongly support this contention. By normalizing other species to $\mathrm{K}$, one can effectively offset possible differences in fire intensity or fuel amount, and correct for "dilution" effects of the smoke. The difference between the normalized values in various fires should then be largely due to the difference in combustion phase. The most revealing results are shown in Table 3. It is striking that the K-normalized levoglucosan concentrations in the smoke aerosols on filters $7,11,15$, and 17 are much higher than those on filters 8,18 , 37,48 , and $56(\mathrm{DL}=0.03)$. This difference strongly supports our earlier assignment of the combustion phase to these samples, i.e., smoldering for the first four samples and flaming for the last five. Furthermore, the K-normalized "total identified carbohydrates" concentrations clearly show the same distinction between the two groups of smoke aerosols. In contrast, oxalate does not show any systematic difference between the two groups; neither does chloride. In fact, there is no such difference with most of the other organic acids and inorganic anions. The only exception is gluconate, which shows a difference between flaming and smoldering fires similar to the carbohydrates. However, the magnitude of this difference is weaker in gluconate than in the carbohydrates. Interestingly, $\mathrm{Ca}$ appears to show a reverse trend, i.e., flaming fires emit much more $\mathrm{Ca}$ than 


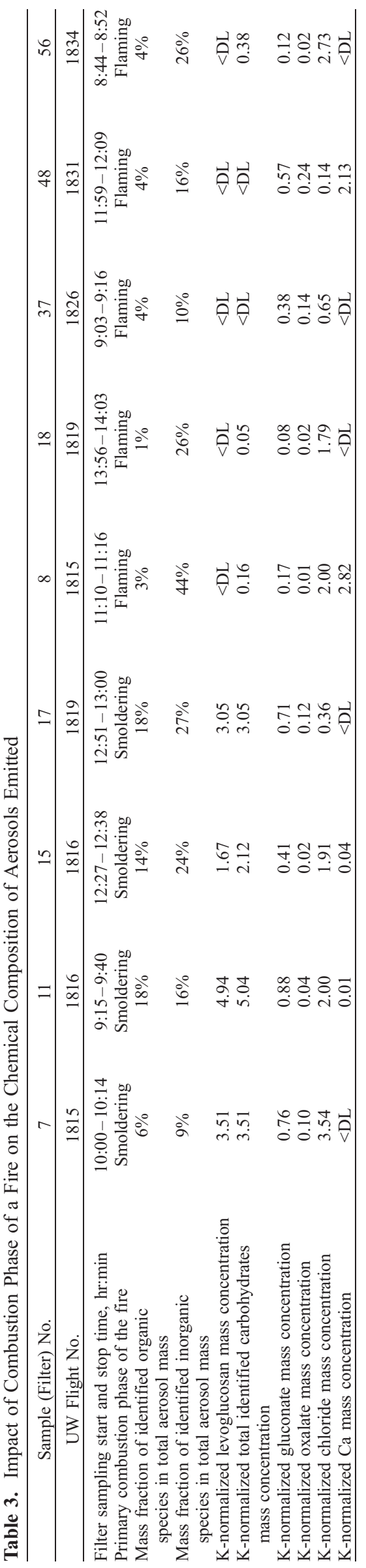

smoldering fires (Table 3). However, for none of the metallic elements do we have enough data for a conclusive analysis.

[28] Previous studies of biomass burning have suggested impact of combustion phase on the chemical composition of fire emissions, particularly the gaseous emissions [Shafizadeh, 1982; Simoneit et al., 1999; Andreae and Merlet, 2001]. The combustion processes are described similarly in these studies and are briefly summarized here. During the initial thermal decomposition, biomass constituents start to hydrolyze, oxidize, dehydrate, and pyrolyze with increasing temperature, forming combustible volatiles, tar (intermediate molecular weight organics), and highly reactive carbonaceous char. When the ignition temperature of the volatile and tarry substance is reached, exothermic reactions (i.e., combustion) begin. During the flaming phase, the initial decomposition products undergo both partial and complete combustion and are converted to simple molecules, particularly $\mathrm{CO}_{2}, \mathrm{H}_{2} \mathrm{O}, \mathrm{NO}_{\mathrm{x}}, \mathrm{N}_{2}$, and $\mathrm{SO}_{2}$. Char formation continues during this stage, which is mainly reducing, resulting in a relatively higher black carbon content. During the smoldering phase, often after the flaming combustion ceases and at lower temperatures, the reactive char and oxygen react gradually at the fuel surface and produce $\mathrm{CO}$ and a large number of partially oxidized species that are similar to the initial decomposition products described above. It is conceivable that more volatile compounds would stay in the gas phase, which has been characterized extensively [Andreae and Merlet, 2001; Yokelson et al., 1996, 1997], whereas less volatile species, such as the carbohydrates and dicarboxylic acids reported in this work, would partition into the aerosol phase.

[29] The fact that levoglucosan, carbohydrate species in general, and gluconate all show a strong relationship with the combustion phase, whereas, other emitted organic acids do not, underlines the complicated chemical reactions involved. Based on past studies and our own analyses, we propose in Figure 8 some possible chemical pathways for the formation of the observed organic species. While these pathways and the detailed reaction mechanisms require further investigations, they can explain most of our observations quite nicely. For example:

[30] The anhydrosugars (e.g., levoglucosan), sugar alcohols (e.g., mannitol), and gluconate have molecular structures very similar to the monomer units of cellulose and hemicellulose, as seen in Figure 5. Energy barriers to break and form bonds to produce these species should be relatively low. Therefore, they are expected to form in large quantities in the more mild combustion stages, e.g., during smoldering combustion or the initial thermal decomposition. The fact that oxygen is more readily available during smoldering burning also helps form or preserve oxygen-rich species such as carbohydrates. In prolonged smoldering fires, further breakdown/oxidation of these primary organics to secondary organics, such as dicarboxylic and monocarboxylic acids, could take place.

[31] Combustion is much more vigorous in the flaming phase. Primary organics, such as anhydrosugars and gluconic acid, are expected to further break down to secondary species, resulting in the production of various organic acids, similar to those present in prolonged smoldering fires. These organic species also lose oxygen to the gas phase 

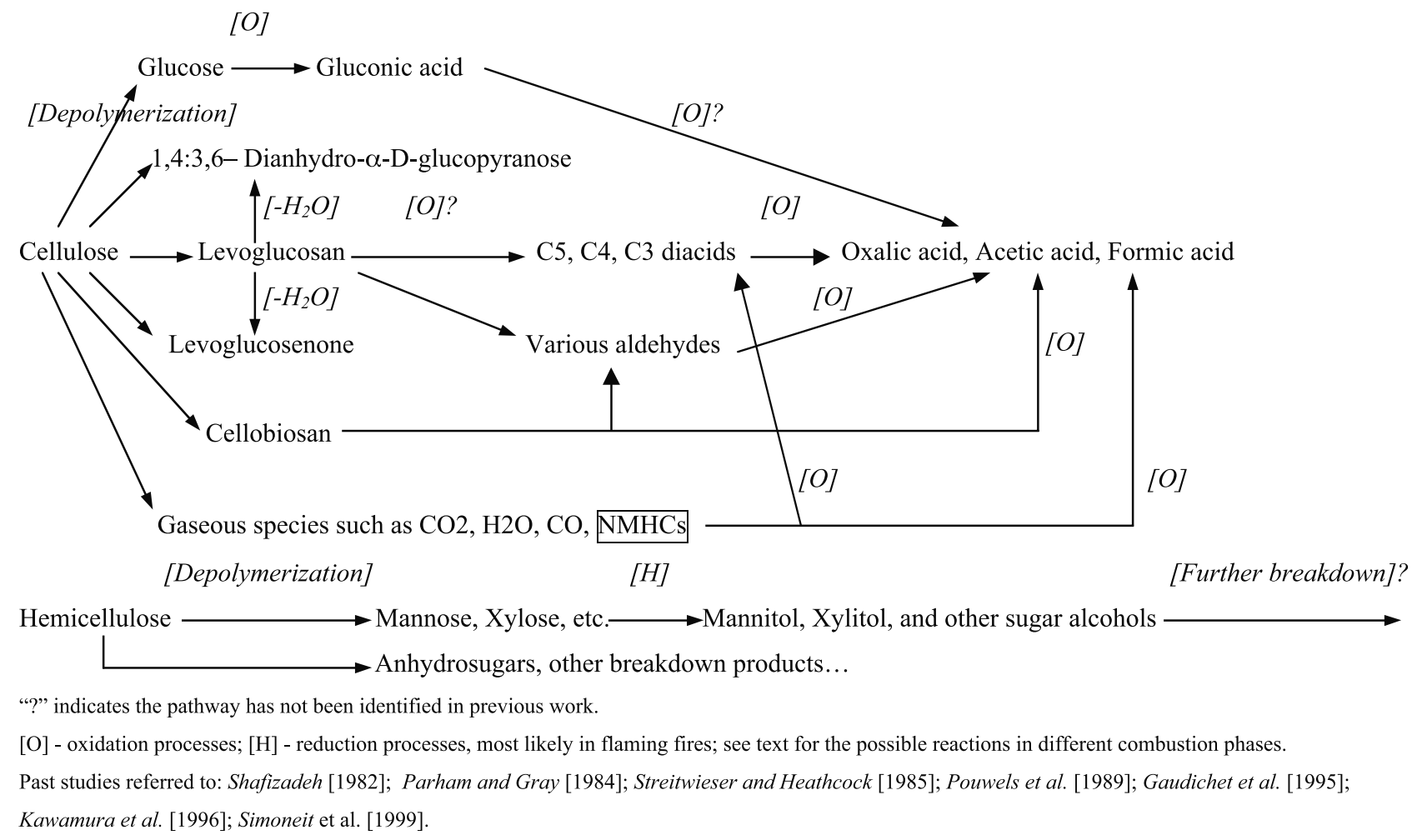

Figure 8. Proposed chemical pathways for the formation of observed organic species in smoke aerosols in SAFARI 2000.

significantly during flaming combustion, contributing to the large production of simple molecules such as $\mathrm{SO}_{2}, \mathrm{NO}_{\mathrm{x}}$, and $\mathrm{CO}_{2}$. As a result, the total organic content is relatively lower in aerosols from flaming fires. Since the amounts of particulate inorganic species appear to be less dependent on combustion phase (Table 3 ), this would also explain why aerosols from flaming fires often have a higher inorganic content than those from smoldering fires.

[32] Since biomass burning aerosols are known to be efficient cloud condensation nuclei (CCN) [e.g., Hobbs and Radke, 1969; Novakov and Corrigan, 1996], the impact of combustion phase on the composition of smoke aerosols could have important climatic consequences. For example, in a region where biomass fires are predominantly in the flaming phase, the activation process of the $\mathrm{CCN}$ could be mainly determined by their inorganic components. For areas impacted mainly by aerosols emitted from smoldering fires, soluble organic species, such as carbohydrates, could play a major role.

\subsection{Chemical Evolution During Initial Aerosol Aging}

[33] Another interesting phenomenon we observed in smoke aerosols is the evolution of various chemical species with the age of smoke. During SAFRAI 2000, a number of smoke samples of known ages were collected downwind of several biomass fires. On 7 September 2000 in South Africa, smoke aerosols were collected over the fire and at 5 and $26 \mathrm{~km}$ from the fire. From the wind speed, these two samples had aging times of about $7 \mathrm{~min}$ and $40 \mathrm{~min}$, respectively. On 1 September in Zambia, smoke aerosols were collected over the fire and at $11 \mathrm{~km}$ from the fire. After correcting the ambient background and normalizing the mass concentrations of measured species to K, these samples show striking patterns during the aging process. In the South Africa case, the mass concentrations of nitrate, oxalate, glutarate, succinate, formate, and levoglucosan increased by at least an order of magnitude after about 40 min of aging. Increases from 3 to 10 times were also observed in the concentrations of acetate, sulfate, and gluconate, as well as the total aerosol mass. These evolution patterns, along with the measurement uncertainties, are shown in Figure 9. The data set from Zambia, although consisting of just two data points, showed the same increasing patterns for all of the species mentioned above. In sharp contrast, the chloride mass concentration deceased by a factor of two after 40 min of aging, although this decreasing trend is not conclusive due to the scarcity of data.

[34] Relatively simple to interpret is the evolution of inorganic species. Measurements taken aboard the Convair 580 (P. Sinha, personal communication) show that abundant $\mathrm{SO}_{2}$ and $\mathrm{NO}_{\mathrm{x}}$ were emitted from the fires studied in SAFARI 2000. It is conceivable that these gases, together with atmospheric oxidants such as $\mathrm{O} 3$ or $\mathrm{HO}$, could dissolve into aqueous aerosols as the smoke cooled, and then be further oxidized to form sulfates and nitrates. Under favorable conditions, sulfates and nitrates could replace chloride, and $\mathrm{HCl}$ would be released into the gas phase. This scenario, which was suggested by Gaudichet et al. [1995], is consistent with our observation of the large increases in sulfate and nitrate and the slight decrease in chloride.

[35] More complicated is the rapid production of organic species such as glutarate, succinate, oxalate, acetate, formate, gluconate, and levoglucosan during the first $40 \mathrm{~min}$ of 


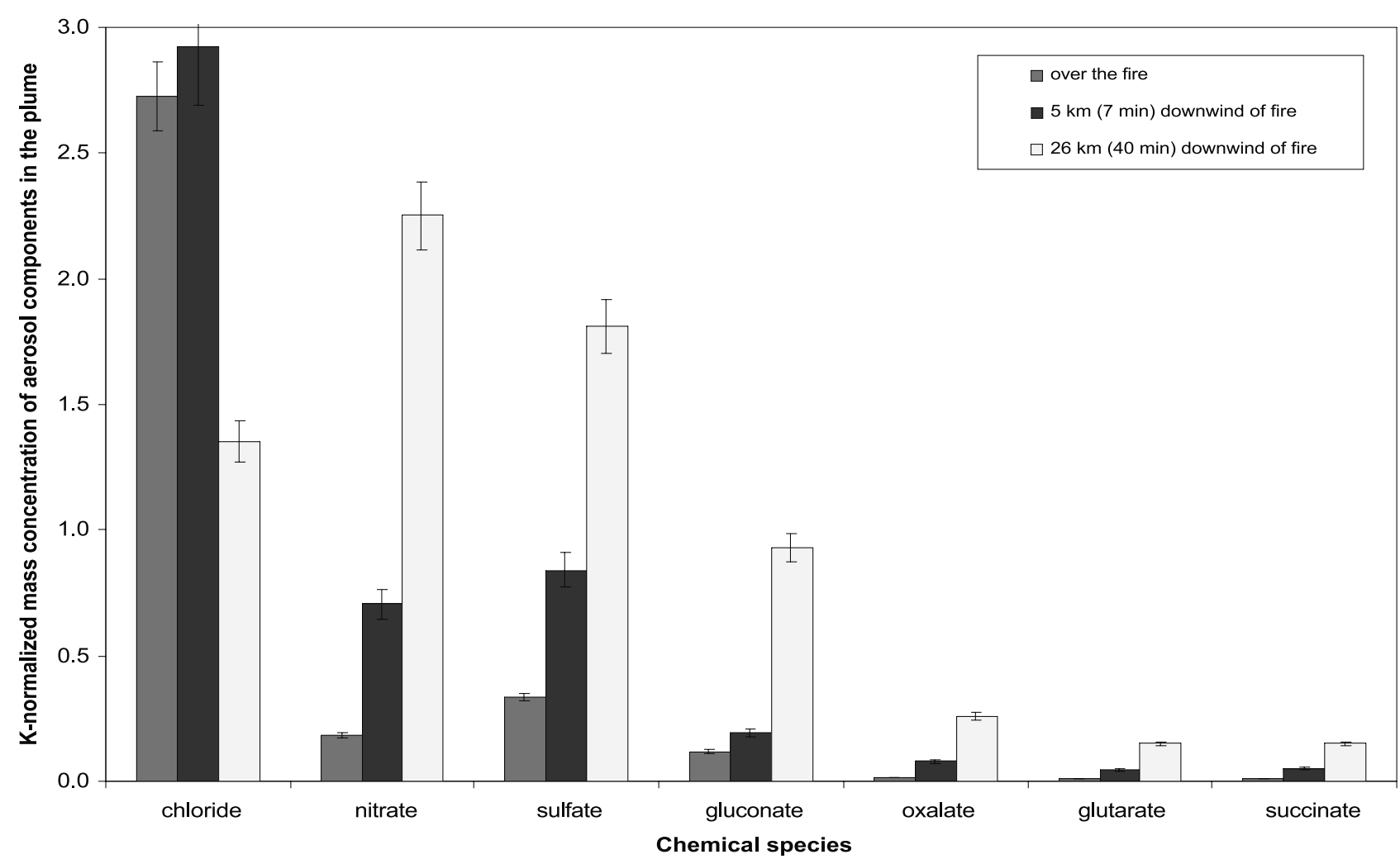

Figure 9. Chemical evolution of several aerosol components in the plume from the savanna fire studied on 7 September 2000 in South Africa.

smoke aging. However, some plausible mechanisms can be suggested to explain these observations. In flames, where the temperature can be as high as $800^{\circ} \mathrm{C}$, biomass could be broken down to a variety of species, ranging from simple molecules such as $\mathrm{CO}$ and $\mathrm{CO}_{2}$, or small organic compounds such as oxalic, acetic, and formic acids, to intermediate organic species such as dehydrated sugars and sugar alcohols, and to even larger species with a partially polymeric nature. For example, cellobiosan, which is a dimer of two glucose units (one in 1,6-anhydro form), has been proposed as an important intermediate species during pyrolysis [Pouwels et al., 1989]. As smoke cools as it moves away from a fire, oxalic, acetic, formic acids may condense onto existing particles, thereby showing increasing trends as smoke ages. This condensation scenario, which was speculated in previous studies [e.g., Reid et al., 1998], could also apply to intermediate species, such as levoglucosan and mannitol. Furthermore, hot vapors of large polymeric and organic species, which have low volatility, might quickly nucleate new particles in the smoke or condense onto existing particles. During aerosol aging, oxidants such as $\mathrm{O}_{2}$ and $\mathrm{HO}$, could further oxidize these large species to smaller molecules through heterogeneous reactions on particle surface, or aqueous reactions inside particles. Our observation of the continuous formation of dicarboxylic acids, gluconate, and levoglucosan during the first 40 min suggests that this is a likely pathway, since the large precursor species are unlikely to exist in the gas phase at ambient temperatures away from the fire.

[36] Additionally, the gaseous NMHC species emitted by biomass fires, particularly the unsaturated compounds such as alkenes, would be transported with smoke aerosols in the plume. During the aging process, they could be oxidized to organic acids in the gas phase and then partition into the aerosol phase, as demonstrated by previous studies [e.g., Gao et al., 2001]. Alternatively, the unsaturated NMHC could first be oxidized to aldehydes or ketones, which could then dissolve into smoke aerosols and be oxidized to organic acids through aqueous-phase reactions. These pathways could also contribute to the increase of formic, acetic, and dicarboxylic acids observed during smoke aging.

\subsection{Some Spatial Distribution Patterns}

[37] It is beyond the scope of this paper to describe the spatial distribution patterns of all the species observed from biomass burning in southern Africa. Instead, we focus here on a few conspicuous patterns of the identified organic species.

[38] Of the seven organic acids, formic acid and acetic acid are the most volatile species and can easily partition between the gas and aerosol phases. Also, sources other than biomass burning can impact their atmospheric concentrations and distributions [Chebbi and Carlier, 1996]. In contrast, $\mathrm{C} 2$ to $\mathrm{C} 5$ dicarboxylic acids mostly remain in the aerosol phase, although they too are believed to have alternate sources such as urban pollution or marine precursors [Grosjean et al., 1978; Kawamura et al., 1996]. A detailed look at the individual diacids in the aerosol samples discussed here shows interesting distribution patterns. In the smoke aerosols, oxalate (C2) was almost always the most abundant species, followed by glutarate (C5) and succinate (C4). Strikingly, malonate (C3) was absent in most smoke 


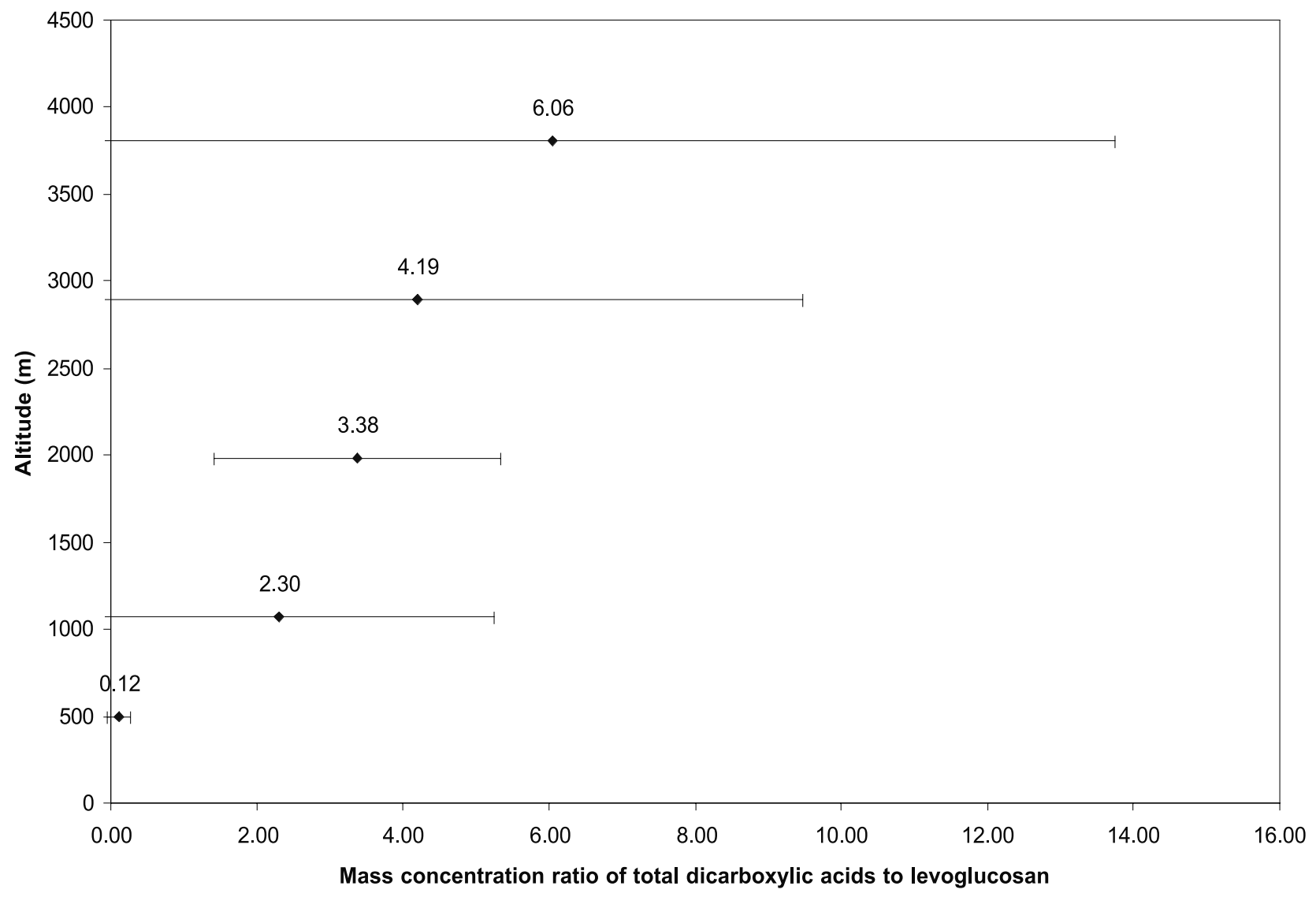

Figure 10. Mass concentration ratio of total dicarboxylic acids to levoglucosan in smoke and haze aerosols collected at various altitudes during SAFARI 2000.

aerosols, including the aged samples. Such a pattern suggests that C5, C4 acids are secondary products in fire plumes, which supports our earlier speculation that larger organic species could be further oxidized to form these acids. A gradual degradation from high to low carbon number species could have delayed the production of malonic acid, which could then have been produced in large amounts only after the first $40 \mathrm{~min}$. On the other hand, numerous breakdown reactions could directly produce oxalic acid, as shown in Figure 8, which could explain why it was the most abundant diacid species. In the haze aerosols, oxalate again often has the highest mass concentrations, but followed by malonate, and then by succinate and glutarate. This implies a possible fractionation pattern during aerosol upward transport. Certain smoke components are first converted by atmospheric oxidants to $\mathrm{C} 5$ diacid, which is then converted to $\mathrm{C} 4$, then $\mathrm{C} 3$, and finally $\mathrm{C} 2$ diacid through sequential decarboxylation and oxidation. This abundance of oxalic and malonic acids has been observed previously in both marine and urban aerosols, which suggests this fractionation pattern of diacids could be quite common in aged, tropospheric aerosols [e.g., Kawamura and Ikushima, 1993; Kawamura and Sakaguchi, 1999]. Oxalic acid, in particular, appears to have at least two sources in southern Africa: primary production during savanna burning and secondary production during aerosol upward transport.

[39] Of the seven carbohydrates, levoglucosan was the most abundance species in the smoke aerosols, followed by 1,4:3,6-dianhydro- $\alpha$-d-glucopyranose, which was emitted at lower concentrations and identified in fewer samples. In haze layers, although levoglucosan was still the most abundant carbohydrate in most aerosol samples, its concentration was about two orders of magnitude lower than in smoke. Interestingly, 1,4:3,6-dianhydro- $\alpha$-d-glucopyranose, levoglucosenone, mannitol, and xylitol were also constantly identified in haze aerosols, sometimes at concentrations comparable to levoglucosan. It is likely that these carbohydrates are secondary species produced during the upward transport of aerosols, although the possibility that they originate from primary emissions of biomass fires cannot be excluded.

[40] We further examine whether there might be some relationship between the dicarboxylic acids and carbohydrates during aerosol upward transport. The mass concentration ratios of total diacids to levoglucosan were determined for both the smoke and haze aerosols. Levoglucosan was chosen because both past studies [e.g., Simoneit et al., 1999] and this work suggest it could be the most abundant and ubiquitous carbohydrate emitted from biomass fires. These ratios were then grouped into several altitude bins: surface-0.6 km (7 samples), $0.6-1.5 \mathrm{~km}$ (3 samples), $1.5-2.4 \mathrm{~km}$ (9 samples), $2.4-3.3 \mathrm{~km}$ (11 samples), 3.3-4.3 km (11 samples). Shown in Figure 10 is the mean ratio in each altitude bin, along with the inter-sample standard deviation, versus the mean altitude. All the fire plume aerosols are assigned an altitude of $500 \mathrm{~m}$ where they 
were generally collected. It is noticeable that with increasing altitude, the mean ratio systematically increases, although the variance of this ratio increases sufficiently to preclude significant differences. Nevertheless, individual data points show that the ratios in the haze aerosols are always higher than in the plume aerosols near the surface.

[41] Several scenarios provide possible explanations for these observations. The height of the midtroposphere inversion varied with weather conditions from day to day during SAFARI 2000, but it was usually between 3-4 km. On many days, the atmosphere over the sampling region was well mixed all the way to this inversion layer. If no urban pollution was present, the observed increase of diacids relative to levoglucosan with altitude raises the possibility that levoglucosan could have been chemically converted to diacids during upward transport. The aldehydes emitted from the fires could also have been oxidized to diacids during the transport process. However, the latter pathway is unlikely once the smoke is dispersed, which usually took place long before the smoke reached the inversion during SAFARI 2000. On the other hand, if urban pollution was significant in the sampling region, cycloalkenes and polyalkenes in the pollution could be converted to diacids in the aerosols through secondary processes. Urban pollution could be a primary source for these diacids as well.

[42] In contrast, on days when the inversion was substantially lower, the observed higher diacid to levoglucosan ratios aloft could be due to long range transport. Certainly, the very large variance aloft indicates that a variety of scenarios are possible in the free troposphere during the dry season in southern Africa. Clearly, meteorological transport and chemical transformations are interconnected, and both must be taken into account to understand the observations.

\section{Summary and Conclusions}

[43] Smoke aerosols from savanna fires and haze aerosols from the surface to the free troposphere were collected in the dry season in southern Africa. These samples were subjected to a suite of chemical analysis methods to speciate water-soluble components. Three inorganic anions, five metallic elements, seven organic acids, and seven carbohydrate species (serving as representatives of their isomers) were identified and quantified. On the average, these species accounted for $27 \%$ and $36 \%$ of the total mass of smoke aerosols and haze aerosols, respectively.

[44] A novel technique, electrospray ionization-ion trap mass spectrometry (ESI-MS), was utilized to detect carbohydrate species. Concurrently used with an ion chromatography system, we identified glucose, three dehydrated sugars, and three sugar alcohols as aerosol components in smoke plume and regional haze. Their mass concentrations, calculated from the MS data, should include their respective isomers, which could also have been present. Levoglucosan was the most abundant carbohydrate species in the smoke aerosols, comprising up to $14 \%$ by mass of aerosols from primarily smoldering fires. It was also a ubiquitous component in haze aerosols in the free troposphere, which suggests the feasibility of using it as a tracer for biomass burning. Furthermore, the identified carbohydrates in the haze layers could be due to both primary emissions as well as secondary production. These findings demonstrate that the ESI-MS has great potential in identifying and quantifying polar and water-soluble species in the atmosphere, which are still poorly understood but whose intrinsically hygroscopic nature could have great impact on the radiative forcing of aerosols.

[45] Of the seven organic acid anions identified, gluconate is tentatively identified as the most abundant species in smoke aerosols. Similar to levoglucosan, it could be a characteristic component of smoke aerosols. Further work to more decisively identify this compound is clearly in order. Considering the ionic nature of gluconate, the negative-ion mode of the EMI-MS is expected to be able to identify it with better sensitivity than the positive ion detection we employed in this work. Coupling this higher sensitivity with IC-PAD should further improve the credibility of the identification. C2 to C5 dicarboxylic acids were identified in both smoke and haze aerosols. They could come from direct fire emissions as well as secondary formation in plumes. In the ambient haze, the mass concentrations of diacids relative to levoglucosan increased with altitude. We propose that under certain condition, some carbohydrates, such as levoglucosan, could have been converted to dicarboxylic acids during aerosol upward transport. These observations suggest that besides urban pollution and marine sources, biomass burning could be another source for these dicarboxylic acids in the atmosphere.

[46] Secondary formation of both inorganic and organic species was observed in the smoke plumes during the initial hour of aerosol aging. We have proposed a number of possible pathways to explain such observations. Further analyses of the organic components in fresh smoke aerosols, some of which could have a polymeric nature, are needed to fully understand the complicated chemical reactions involved in smoke plumes. Such an aerosol aging process, which has been observed in both southern Africa and South America, could be important for climate models. Aged smoke aerosols, with a high content of water-soluble and thus hygroscopic inorganic and organic species, could have a substantial impact on indirect as well as direct aerosol radiative forcing.

[47] The mass fraction of organic species was significantly higher in aerosols emitted from primarily smoldering fires than from flaming fires. This impact of combustion phase on the chemical composition of smoke aerosols could have important climatic consequences as well. For example, in a region where biomass fires are primarily flaming, the emitted aerosols could have different $\mathrm{CCN}$ efficiencies from those in regions with primarily smoldering fires.

[48] Acknowledgments. We thank the UW Convair-580 research and flight crew for their effort in obtaining field measurements described in this paper. The field studies were supported by grants NAG-5-9022 and NAG5-7675 from NASA's Radiation Science Program and grant ATM-9901624 from NSF's Division of Atmospheric Sciences. Support for the chemical analysis of the aerosol samples was provided by the ONR grant N0001497-1-0132 and NSF grant ATM-9908411. The Esquire LC electrospray source-ion trap mass spectrometer was purchased with support from NSF under Grant No. 9807748. This study is part of the SAFARI 2000 Southern African Regional Science Initiative.

\section{References}

Andreae, M. O., Biomass burning: Its history, use, and distribution and its impact on environmental quality and global climate, in Global Biomass Burning, edited by J. S. Levine, pp. 3-21, MIT Press, Cambridge, Mass., 1991. 
Andreae, M. O., and P. Merlet, Emission of trace gases and aerosols from biomass burning, Global Biogeochem. Cycles, 15, 955-966, 2001.

Andreae, M. O., et al., Airborne studies of aerosol emissions from savanna fires in southern Africa, 2, Aerosol chemical composition, J. Geophys. Res., 103, 32,119-32,128, 1998.

Andreae, M. O., E. Atlas, H. Cachier, W. R. Cofer III, G. W. Harris, G. Helas, R. Koppmann, J.-P. Lacaux, and D. E. Ward, Trace gas and aerosol emissions from savanna fires, in Biomass Burning and Global Change, edited by J. S. Levine, pp. 278-295, MIT Press, Cambridge, Mass., 1996.

Barinaga, C. J., C. G. Edmonds, H. R. Udseth, and R. D. Smith, Sequence determination of multiply charged peptide molecular ions by electrospray-ionization tandem mass spectrometry, Rapid Commun. Mass Spectrom., 3, 160-164, 1989.

Cachier, H., C. Liousse, and P. Buat-Menard, Particulate content of savanna fire emissions, J. Atmos. Chem., 22, 123-148, 1995.

Chapman, E. G., C. J. Barinaga, H. R. Udseth, and R. D. Smith, Confirmation and quantitation of hydroxymethanesulfonate in precipitation by electrospray ionization-tandem mass spectrometry, Atmos. Environ., 24A, 2951-2957, 1990.

Chebbi, A., and P. Carlier, Carboxylic acids in the troposphere, occurrence, sources, and sinks: A review, Atmos. Environ., 30, 4233-4249, 1996.

Crutzen, P. J., and M. O. Andreae, Biomass burning in the tropics: Impact on atmospheric chemistry and biogeochemical cycles, Science, 250, 1669-1678, 1990.

Decesari, S., M. C. Facchini, S. Fuzzi, and E. Tagliavini, Characterization of water-soluble organic compounds in atmospheric aerosols: A new approach, J. Geophys. Res., 105, 1481-1489, 2000.

Facchini, M. C., S. Decesari, M. Mircea, S. Fuzzi, and G. Loglio, Surface tension of atmospheric wet aerosol and cloud/fog droplets in relation to their organic carbon content and chemical composition, Atmos. Environ., 34, 4853-4857, 2000.

Gaskell, S. J., Electrospray: Principle and practice, J. Mass Spectrom., 32, 677-688, 1997.

Gao, S., D. A. Hegg, G. Frick, P. F. Caffrey, L. Pasternack, C. Cantrell W. Sullivan, J. Ambrusko, T. Albrechcinski, and T. W. Kirchstetter, Experimental and modeling studies of secondary organic aerosol formation and some applications to the marine boundary layer, J. Geophys. Res., $106,27,619-27,634,2001$

Gaudichet, A., F. Echalar, B. Chatenet, J. P. Quisefit, G. Malingre, H. Cachier, P. Buat-Menard, P. Artaxo, and W. Maenhaut, Trace elements in tropical African savanna biomass burning aerosols, J. Atmos. Chem., 22, 19-39, 1995.

Graedel, T. E., D. T. Hawkins, and L. D. Claxton, Atmospheric Chemical Compounds-Sources, Occurrence, and Bioassay, Academic, San Diego, Calif., 1986.

Grosjean, D., K. V. Cauwenberghe, J. P. Schmid, P. E. Kelley, and J. N. Pitts Jr., Identification of $\mathrm{C}_{3}-\mathrm{C}_{10}$ aliphatic dicarboxylic acids in airborne particulate matter, Environ. Sci. Technol., 12, 313-317, 1978.

Hobbs, P. V., and L. F. Radke, Cloud condensation nuclei from a simulated forest fire, Science, 163, 279-280, 1969.

Intergovernmental Panel on Climate Change (IPCC) Working Group I, Climate change 2001: The scientific basis, in IPCC Third Assessment Report, Cambridge Univ. Press, New York, 2001.

Kawamura, K., and K. Ikushima, Seasonal changes in the distribution of dicarboxylic acids in the urban atmosphere, Environ. Sci. Technol., 27, 2227-2235, 1993.

Kawamura, K., and F. Sakaguchi, Molecular distributions of water soluble dicarboxylic acids in marine aerosols over the Pacific Ocean including tropics, J. Geophys. Res., 104, 3501-3509, 1999.

Kawamura, K., R. Seméré, Y. Imai, Y. Fujii, and M. Hayashi, Water soluble dicarboxylic acids and related compounds in Antartic aerosols, J. Geophys. Res., 101, 18,721-18,728, 1996.

Lacaux, J. P., H. Cachier, and R. Delmas, Biomass burning in Africa: An overview of its impact on atmospheric chemistry, in Fire in the Environment: The Ecological, Atmospheric and Climatic Importance of Vegeta- tion Fires, edited by P. J. Crutzen and J. Goldammer, pp. 159-191, John Wiley, New York, 1993.

Liousse, C., C. Devaux, F. Dulac, and H. Cachier, Aging of savanna biomass burning aerosols: Consequences on their optical properties, J. Atmos. Chem., 22, 1-17, 1995.

Liousse, C., J. E. Penner, J. J. Walton, H. Eddleman, C. Chuang, and H. Cachier, Modeling biomass burning aerosols, in Biomass Burning and Global Change, edited by J. S. Levine, pp. 492-508, MIT Press, Cambridge, Mass., 1996.

Maruyama, K., M. Yuan, and A. Otsuki, Seasonal changes in ethylene oxide chain length of poly(oxyethylene)alkylphenyl ether nonionic surfactants in three main rivers in Tokyo, Environ. Sci. Technol., 34, 343$348,2000$.

Novakov, T., and C. E. Corrigan, Cloud condensation nucleus activity of the organic component of biomass smoke particles, Geophys. Res. Lett., 23, 2141-2144, 1996.

Novakov, T., D. A. Hegg, and P. V. Hobbs, Airborne measurements of carbonaceous aerosols on the East Coast of the United States, J. Geophys. Res., 102, 30,023-30,030, 1997.

Parham, R. A., and R. L. Gray, Formation and structure of wood, in Chemistry of Solid Wood, Adv. Chem. Ser., vol. 207, edited by R. Rowell, pp. 3-56, Am. Chem. Soc., Washington, D. C., 1984.

Pouwels, A., G. B. Eijkel, and J. J. Boon, Curie-point pyrolysis-capillary gas chromatography-high-resolution mass spectrometry of microcrystalline cellulose, J. Anal. Appl. Pyrol., 14, 237-280, 1989.

Reid, J. S., P. V. Hobbs, R. J. Ferek, D. R. Blake, J. V. Martins, M. R. Dunlap, and C. Liousse, Physical, chemical, and optical properties of regional hazes dominated by smoke in Brazil, J. Geophys. Res., 103, 32,059-32,080, 1998 .

Rogers, C. E., J. G. Hudson, B. Zielinska, R. L. Tanner, J. Hallett, and J. G. Watson, Cloud condensation nuclei from biomass burning, in Global Biomass Burning, edited by J. S. Levine, pp. 432-438, MIT Press, Cambridge, Mass., 1991.

Ruellan, S., H. Cachier, A. Gaudichet, P. Masclet, and J. P. Lacaux, Airborne aerosols over central Africa during the Experiment for Regional Sources and Sinks of Oxidants (EXPRESSO), J. Geophys. Res., 104, $30,673-30,690,1999$

Saxena, P., and L. M. Hildemann, Water-soluble organics in atmospheric particles: A critical review of the literature and application of thermodynamics to identify candidate compounds, J. Atmos. Chem., 24, 57109,1996

Shafizadeh, F., Introduction to pyrolysis of biomass, J. Anal. Appl. Pyrol., 3, 283-305, 1982.

Simoneit, B. R. T., J. J. Schauer, C. C. Nolte, D. R. Oros, V. O. Elias, M. P. Fraser, W. F. Rogge, and G. R. Cass, Levoglucosan, a tracer for cellulose in biomass burning and atmospheric particles, Atmos. Environ., 33, $173-$ $182,1999$.

Streitwieser, A., and C. H. Heathcock, Introduction to Organic Chemistry, 3rd edn., Macmillan, Old Tappan, N. J., 1985.

Wauters, E., E. Vangaever, P. Sandra, and M. Verzele, Polar organic fraction of air particulate matter, J. Chromatogr., 170, 125-131, 1979.

Yokelson, R. J., D. W. T. Griffith, and D. E. Ward, Open-path Fourier transform infrared studies of large-scale laboratory biomass fires, J. Geophys. Res., 101, 21,067-21,080, 1996

Yokelson, R. J., R. Susott, D. E. Ward, J. Reardon, and D. W. T. Griffith, Emissions from smoldering combustion of biomass measured by openpath Fourier transform infrared spectroscopy, J. Geophys. Res., 102, $18,865-18,877,1997$.

S. Gao and M. Sadilek, Department of Chemistry, University of Washington, Seattle, WA, USA.

D. A. Hegg, P. V. Hobbs, and B. I. Magi, Department of Atmospheric Sciences, University of Washington, Box 351640, Seattle, WA 98195-1640, USA. (deanhegg@atmos.washington.edu)

T. W. Kirchstetter, Lawrence Berkeley National Laboratory, Berkeley, CA, USA. 